\title{
Microphysical properties of frozen particles inferred from Global Precipitation Measurement (GPM) Microwave Imager (GMI) polarimetric measurements
}

\author{
Jie Gong ${ }^{1,2}$ and Dong $\mathbf{L}$. Wu ${ }^{2}$ \\ ${ }^{1}$ Universities Space Research Association, Columbia, MD, USA \\ ${ }^{2}$ Climate and Radiation Laboratory, NASA Goddard Space Flight Center, Greenbelt, MD, USA \\ Correspondence to: Jie Gong (jie.gong@nasa.gov) \\ Received: 30 August 2016 - Discussion started: 21 September 2016 \\ Revised: 10 January 2017 - Accepted: 30 January 2017 - Published: 23 February 2017
}

\begin{abstract}
Scattering differences induced by frozen particle microphysical properties are investigated, using the vertically $(\mathrm{V})$ and horizontally $(\mathrm{H})$ polarized radiances from the Global Precipitation Measurement (GPM) Microwave Imager (GMI) 89 and $166 \mathrm{GHz}$ channels. It is the first study on frozen particle microphysical properties on a global scale that uses the dual-frequency microwave polarimetric signals.

From the ice cloud scenes identified by the $183.3 \pm 3 \mathrm{GHz}$ channel brightness temperature $\left(T_{\mathrm{b}}\right)$, we find that the scattering by frozen particles is highly polarized, with $\mathrm{V}-\mathrm{H}$ polarimetric differences (PDs) being positive throughout the tropics and the winter hemisphere mid-latitude jet regions, including PDs from the GMI 89 and $166 \mathrm{GHz}$ TBs, as well as the PD at $640 \mathrm{GHz}$ from the ER-2 Compact Scanning Submillimeter-wave Imaging Radiometer (CoSSIR) during the TC4 campaign. Large polarization dominantly occurs mostly near convective outflow regions (i.e., anvils or stratiform precipitation), while the polarization signal is small inside deep convective cores as well as at the remote cirrus region. Neglecting the polarimetric signal would easily result in as large as $30 \%$ error in ice water path retrievals. There is a universal "bell curve" in the $\mathrm{PD}-\mathrm{TB}_{\mathrm{V}}$ relationship, where the PD amplitude peaks at $\sim 10 \mathrm{~K}$ for all three channels in the tropics and increases slightly with latitude (2-4 K). Moreover, the $166 \mathrm{GHz}$ PD tends to increase in the case where a melting layer is beneath the frozen particles aloft in the atmosphere, while $89 \mathrm{GHz}$ PD is less sensitive than $166 \mathrm{GHz}$ to the melting layer. This property creates a unique PD feature for the identification of the melting layer and stratiform rain with passive sensors.
\end{abstract}

Horizontally oriented non-spherical frozen particles are thought to produce the observed PD because of different ice scattering properties in the $\mathrm{V}$ and $\mathrm{H}$ polarizations. On the other hand, turbulent mixing within deep convective cores inevitably promotes the random orientation of these particles, a mechanism that works effectively in reducing the PD. The current GMI polarimetric measurements themselves cannot fully disentangle the possible mechanisms.

\section{Introduction}

Cloud processes play an instrumental role in determining the surface precipitation characteristics (Rutledge and Hobbs, 1983; Gedzelman and Arnold, 1994; Igel et al., 2013; Tao et al., 2013). In particular, cloud ice processes are arguably among the most poorly understood, in part due to various ice crystal types and sizes, as well as multiple pathways in ice particle formation and evolution. While ice microphysical processes themselves cannot be readily observed from space, the integrated effects of these processes (e.g., cloud and precipitation structures, microphysical/macrophysical properties) can be inferred using remote sensing techniques (e.g., passive, active, multiple instruments).

It is imperative to distinguish between ice cloud and frozen precipitation in the atmosphere although they are both composed of various non-spherical particles (Wallace and Hobbs, 2006). Weather and climate models treat these hydrometeors quite differently by suspending ice clouds for a long duration but removing frozen precipitation unrealistically quickly 
(Li et al., 2013). The models account for ice clouds in radiation calculations but often ignore the radiative fluxes and heating rates from frozen precipitation in the air (Waliser et al., 2012). Hence, remote sensing of microphysical properties in frozen precipitation and their connection to ice clouds above and surface precipitation, like this work, will provide a valuable surrogate for climate models in representing cloudprecipitation processes.

Retrieving microphysical properties of frozen precipitation has been a challenge for spaceborne remote sensing. It depends not only on macrophysical variables (e.g., column integrated mass amount, particle size distribution), but also on frozen particle shape and orientation (Comstock et al., 2007). Small pristine ice particles are observed with no preferred orientation when the ambient temperature is very cold, but become more horizontally oriented in warmer ice clouds (Noel and Chepfer, 2010). On the other hand, for large ice particles such as snow aggregates, it is often difficult to determine their orientation due to irregular shapes that are subject more to aerodynamic conditions than temperature (Xie, 2012).

Passive and active microwave techniques at high frequencies $(>89 \mathrm{GHz})$ are proven to be quite valuable for ice cloud and snowfall remote sensing because of the dominance of ice scattering, whereas low-frequency microwave channels are more suitable for detecting liquid precipitation and water clouds (Skofronick-Jackson and Wang, 2000; Wu and Jiang, 2004). To infer the particle shape and orientation properties, polarimetric measurements are needed and have been explored in a number of earlier studies. For example, Czekala (1998) pointed out the possibility of using off-nadir paired polarized channels at $200-340 \mathrm{GHz}$ to measure horizontally oriented ice crystals. Recently, Miao et al. (2003), Xie and Miao (2011), and Xie et al. (2012) applied a radiative transfer model to ground-based measurements, and found up to $-10 \mathrm{~K}$ polarization differences between the vertically $(\mathrm{V})$ and horizontally $(\mathrm{H})$ polarimetric (V-pol and H-pol, hereafter) observations at $150 \mathrm{GHz}$ during snowfall events. For spaceborne remote sensing, Prigent et al. $(2001,2005)$ analyzed the polarimetric observations at 37 and $85 \mathrm{GHz}$ from SSMI/S (Special Sensor Microwave Imager Sounder) and $85 \mathrm{GHz}$ from TRMM-TMI (Tropical Rainfall Measurement Mission Microwave Imager), where they attributed significant polarimetric differences to horizontally oriented non-spherical liquid or frozen precipitating particles (Prigent et al., 2001, 2005). Defer et al. (2014) found similar amplitudes of polarimetric signals at 89 and $157 \mathrm{GHz}$ using the MADRAS (Microwave Analysis and Detection of Rain and Atmospheric Structures) instrument onboard the Megha-Tropiques Mission. Studies using groundbased radar also suggested similar polarimetric difference distribution (e.g., Homeyer and Kumjian, 2015). Davis et al. (2005) studied the $122 \mathrm{GHz}$ polarimetric radiances at a very large oblique view angle and found noticeable differences between $\mathrm{V}$ - and $\mathrm{H}$-pol measurements, supporting the global presence of horizontally aligned ice particles in the upper troposphere. In a further study with Monte Carlo simulations, Davis et al. (2007) showed that such a polarimetric difference remains detectable at $190-664 \mathrm{GHz}$ from large oblique angles. In addition to the microwave techniques, lidar polarimetry at visible channels has also been used to infer ice particle orientation (e.g., Hu, 2007; Noel and Chepfer, 2010; Zhou et al., 2012, 2013), but is limited to the top layer of ice clouds due to poor cloud penetration with lidar techniques. Microwave polarimetric observations at 90$200 \mathrm{GHz}$ are capable of penetrating thick clouds, and yet are very much under-utilized. With careful consideration of surface or liquid cloud effects, these polarimetric measurements can provide useful information on the shape and orientation of frozen particles in the atmosphere.

The launch of the Global Precipitation Measurement (GPM) core satellite in February 2014 enables new investigations of microphysical properties of frozen ice particles and their connection to surface precipitation. Conically polarimetric scanning at high microwave frequencies (89 and $166 \mathrm{GHz}$ ) from the GPM's Microwave Imager (GMI) enhances sensitivity to frozen precipitation particle scattering and preserves the polarimetric information from ice clouds. Combining with GMI radiances at low microwave frequencies and GPM radar reflectivity, simultaneous retrievals of frozen particle microphysical properties (e.g., bulk size and orientation parameters) can be achieved on a global basis.

In this paper we present an analysis of the global GMI's polarimetric measurements at 89 and $166 \mathrm{GHz}$ to infer the microphysical properties of frozen particles above precipitating systems. In the analysis we also include the airborne $640 \mathrm{GHz}$ polarimetric observations from NASA's Compact Scanning Submillimeter-wave Imaging Radiometer (CoSSIR) instrument to extend the sensitivity to small ice crystals. Horizontally oriented non-spherical frozen particles and the mixing induced by vertical motion are thought to be the leading causes of the observed radiance polarimetric differences. Radiative transfer models (RTMs) are employed to further quantify these hypotheses.

This paper is organized to describe the data analysis technique and radiative transfer models in Sect. 2, followed by the GMI and CoSSIR observation results in Sect. 3. The working hypotheses on the observed polarized signals are discussed in the subsequent section, with conclusions and future directions in the end.

\section{GMI data, analysis, and radiative transfer models}

\subsection{GMI polarimetric measurements}

The GPM core satellite consists of a dual-frequency precipitation radar (DPR) and a passive GMI instrument with 13 channels between 10 and $190 \mathrm{GHz}$, among which the $10.65,18.7,36.5,89$, and $166 \mathrm{GHz}$ channels have $\mathrm{V}$ - and $\mathrm{H}-$ 
polarizations. In this study, we use only the 89 and $166 \mathrm{GHz}$ polarization data because at these high frequencies the scattering contributions from ice particles and frozen precipitation become significant. The GPM core satellite flies at an altitude of $407 \mathrm{~km}$ in a non-Sun-synchronized orbit, covering a latitude range of $68^{\circ} \mathrm{S}$ to $68^{\circ} \mathrm{N}$. Its slow progressing rate over local time makes it feasible to study the diurnal variability of cloud and precipitation. Its wider-than-TRMM latitude coverage now allows investigations of cloud/precipitation properties in the extra-tropics. The GMI has a forward conical scan off-nadir at an angle of $48.5^{\circ}\left(52.8^{\circ}\right.$ incidence angle at the surface). GMI contains two sets of footprint sizes with different scan swaths. For low-frequency (LF) channels below and including $89 \mathrm{GHz}$, the scan swath is $885 \mathrm{~km}$, but it becomes $835 \mathrm{~km}$ for high-frequency (HF) channels. Such a disparity in footprint size and swath requires post-processing and regridding of the raw radiance measurements (L1B) in order to intercompare the 89 and $166 \mathrm{GHz}$ polarimetric measurements. Thus, we choose to use L1C-R product instead of L1B in our study. More details on comparing the 89 and $166 \mathrm{GHz}$ datasets can be found in Appendix A.

In this study we define the polarimetric radiance difference (PD) as $\Delta T_{\mathrm{b}}=\mathrm{TB}_{\mathrm{V}}-\mathrm{TB}_{\mathrm{H}}$. Figure 1 shows a squall line event revealed in the GMI's dual-pol 89 and $166 \mathrm{GHz}$ radiances and PDs on 29 April 2014. The squall line exhibits a clear center line of deep convective cells and a periphery of anvil clouds in the radiance maps (Fig. 1a and b), where brightness temperature $\left(T_{\mathrm{b}}\right)$ is depressed strongly in both channels but their PDs are relatively small along the deep convective line for both channels. Away from this convective center line, PDs maximize in the anvil/stratiform precipitation region (on the order of $10 \mathrm{~K}$ ) before diminishing gradually in the remote clear-sky/cirrus regions $(0-5 \mathrm{~K})$. This variation from convective cores to anvil outflow and further to clear sky is more obviously seen in the $166 \mathrm{GHz}$ than the $89 \mathrm{GHz}$ maps, because of the increasing contribution of ice particle scattering at higher-frequency microwave channels. It is also evident in Fig. 1c, where the $89 \mathrm{GHz}$ PDs are more sensitive to polarimetric signals from ocean surfaces than the $166 \mathrm{GHz}$, exhibiting a large PD contrast between land and ocean (note that the dark-red colored ocean observations in Fig. 1c actually far exceeded the color-bar range. In order to emphasize the common features and disparities of the PD distribution, we chose to keep the same color bar for Fig. 1c and $d$ though). Such a land-ocean contrast is not readily seen in the $T_{\mathrm{b}}$ maps.

Capable of penetrating clouds though, the PDs from 89 and $166 \mathrm{GHz}$ contain surface polarization signals that need to be taken into account prior to cloud analyses. The polarized surface contributions are particularly strong over water where the degree of linear polarization (DoLP) of microwave radiances depends on surface roughness induced by wind and sea foams (Meissner and Wentz, 2012; Chen, 2014). As seen in Fig. 1c, the $89 \mathrm{GHz}$ PDs exhibit a large contrast between land and ocean, but such a contrast disappears at $166 \mathrm{GHz}$. (a) $89 \mathrm{GHz}(\mathrm{V})$

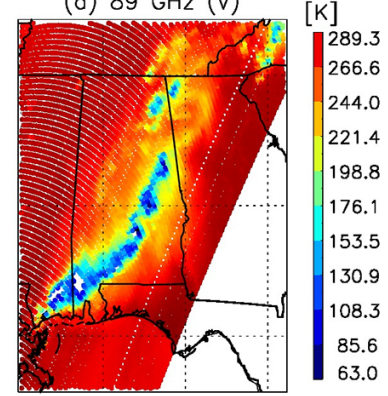

(c) $89 \mathrm{GHz}(\mathrm{V}-\mathrm{H})$

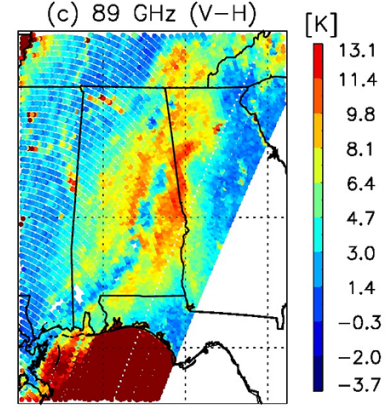

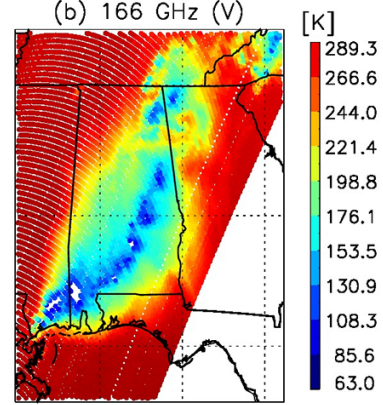

(d) $166 \mathrm{GHz}(\mathrm{V}-\mathrm{H})$

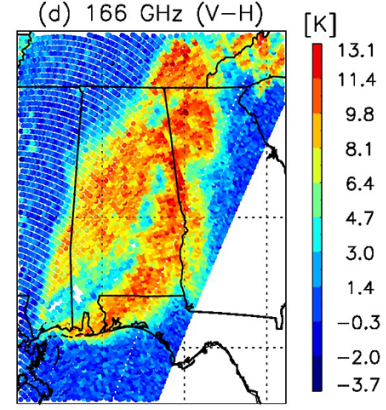

(b) $166 \mathrm{GHz}(\mathrm{V})$

Figure 1. A squall line event on 29 April 2014 passing through the southeastern US as observed with GMI $89 \mathrm{GHz}$ (left panels) and $166 \mathrm{GHz}$ (right panels) polarimetric channels. The GMI observed radiance distributions and polarimetric differences (PDs) are shown at the top and bottom, respectively. The dark-red area over the ocean in panel (c) greatly exceeds the color scale, with values mostly in the range of 16-29 K. They are presented by the black open dots in Fig. 2.

This feature is again manifested in Fig. 2, where observations over ocean, marked by black open circles, spread to large PDs at the warmest end from $89 \mathrm{GHz}$ observations, while this branch is not distinguishable at $166 \mathrm{GHz}$.

To study scattering properties of cloud and frozen particles jointly with 89 and $166 \mathrm{GHz}$, we need to isolate cloud cases from the clear sky where the surface contributions are not negligible. To flag heavy cloudy cases, we use the simultaneous $183.3 \pm 3 \mathrm{GHz}$ measurements, which show little sensitivity to surface emission due to the strong water vapor absorption but still with enough sensitivity to deep convective clouds. As described in Gong and Wu (2013), a "3 $\sigma$ method" can be used to distinguish between clear- and cloudy-sky scenes for the Microwave Humidity Sounder (MHS) tropical observations. The $3 \sigma$ method first identifies the peak $\left(\mathrm{TB}_{0}\right)$ and standard deviation $(\sigma)$ of the probability density function (PDF) of a month-long radiance observation in a given region or a latitude belt, and then the cloudy-sky scene is defined at places where $T_{\mathrm{b}}<\mathrm{TB}_{0}-3 \sigma$. In this study, we apply the same methodology to select cloudy-sky scenes. Cloud occurring frequency after applying this $3 \sigma$ method is comparable to that observed by CloudSat radar (see Appendix D for a detailed map). Because of ocean-land differences, separate PDFs are computed for ocean and land surfaces in 

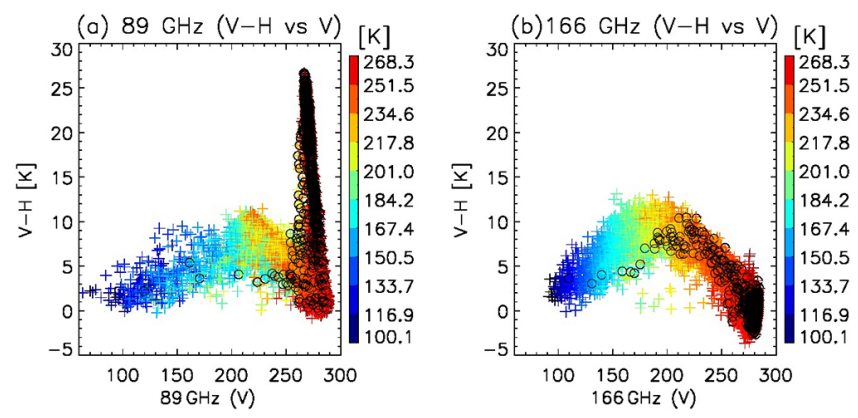

Figure 2. The PD-TBV scatter plots for the squall line case shown in Fig. 1 from $89 \mathrm{GHz}$ (a) and $166 \mathrm{GHz}$ (b). The points are colorcoded by $183.3 \pm 3 \mathrm{GHz} T_{\mathrm{b}}$. Observations over the ocean are further marked by black open circles.

each $10^{\circ}$ latitude bin. The three GMI channels $(89,166$, and $183 \mathrm{GHz})$ have roughly the same $(7.2 \mathrm{~km} \times 4.4 \mathrm{~km})$ footprint size, which minimizes the sampling error due to beam-filling effects between different frequencies. The combined sensitivities of the three channels will help to distinguish the scattering differences between frozen precipitation (large particles) and ice clouds (small ice crystals).

As a caveat, GMI swaths are mismatched between the LF and $\mathrm{HF}$ channels, offset by as much as $4^{\circ}$ in pointing (L1C, ATBD). Therefore, the L1C data are not appropriate for joint analyses of 89, 166 and $183 \mathrm{GHz}$ measurements. Instead, we use the L1C-R product that is derived from the L1B radiances using the nearest-neighborhood matching method to register collocated LF and HF observations. This re-registration procedure eliminates $\sim 7 \%$ of the data, of which most occur at the edge of the LF scan swath. These missing data do not impact our climatological study. A comparison of the L1C-R and L1B datasets is given in Appendix A.

While the 89 and $166 \mathrm{GHz}$ polarimetric measurements are useful to infer microphysical properties of frozen precipitation, PD at a higher frequency can reveal cloud properties with smaller ice crystals. To expand our study to ice clouds with small ice crystals (e.g., cirrus), we also include an analysis of the $640 \mathrm{GHz} \mathrm{V}$ - and H-pol data acquired by the NASA airborne Compact Scanning Submillimeter-wave Imaging Radiometer (CoSSIR) during the Tropical Composition, Cloud and Climate Coupling (TC4) campaign in JulyAugust 2007 (Evans et al., 2005, 2012). The CoSSIR instrument had a similar conical scan geometry to the GMI in both the forward and backward directions. About $\sim 39000 \mathrm{CoS}-$ SIR conical samples from three TC4 flights are analyzed. These samples were mostly over the Pacific Ocean near central America and large enough to be commensurate with the GMI statistics over the tropical oceans. We found that CoSSIR measurements were unreliable during the ascent/descent flight in altitude, and therefore only measurements at a cruise altitude above $19 \mathrm{~km}$ are used.

\subsection{Data analysis}

The PD-TBV relationship is a very useful diagnostic tool and will be used throughout this study. Figure 2 shows a scatter plot of PD vs. PD-TBV from the same squall line event reported in Fig. 1. As expected, for large oceanic PDs seen at $89 \mathrm{GHz}$, there is a distinct branch in Fig. 2a, showing a strong linear $\mathrm{PD}-\mathrm{TB}_{\mathrm{V}}$ relationship at the warm or clear-sky TBs that corresponds to the surface polarization signals. This branch is separated from the frozen particle scattering cluster that exhibits a bell curve in the $\mathrm{PD}-\mathrm{TB}_{\mathrm{V}}$ relationship. The bell curve is characterized by a peak of $\mathrm{PD}=\sim 10 \mathrm{~K}$ at $\mathrm{TB}_{v}=220 \mathrm{~K}$. Note that the surface branch is absent at $166 \mathrm{GHz}$ due to strong water vapor absorption in the subtropics (Fig. 2b), but the bell curve is similar to the one at $89 \mathrm{GHz}$, with a peak of $\mathrm{PD}=\sim 10 \mathrm{~K}$ at $\mathrm{TB}_{v}=190 \mathrm{~K}$. The common bell curve indicates that PD is small in the warmest (i.e., thin cloud or clear-sky) and coldest $T_{\mathrm{b}}$ (i.e., deep convection) cases. As shown in the later sections, the bell curve appears to be universal at all latitudes.

The PDs observed from a conical scan are mostly positive in cloudy-sky scenes, because the cloud scattering tends to produce a larger $T_{\mathrm{b}}$ depression due to horizontally oriented non-spherical frozen particles. It is non-trivial to determine the magnitude of PD because other factors may play an important role as well. For example, as we can see from Fig. 1c, PDs are larger at $89 \mathrm{GHz}$ over the ocean because of higher Vpol emissivity on calm water surfaces (acting like a mirror) than on windy surfaces, whereas land surfaces generally have little polarization due to surface roughness. In addition, liquid clouds and moisture layers may attenuate the PD signal from the surface (Wu and Jiang, 2004). Negative PD values can be found in the GMI data as well, but they are mostly in the clear-sky measurements and affected by noise. The PDF of negative PDs at 89 and $166 \mathrm{GHz}$ behaves like a Gaussian distribution in most cases (Appendix B), from which we estimate the PD noise level to be $\sim 0.5 \mathrm{~K}$ for $89 \mathrm{GHz}$ and $\sim 1 \mathrm{~K}$ for $166 \mathrm{GHz}$. It is interesting to observe that in some locations the negative PDs are non-Gaussian and have a significant number of measurements deviate from the Gaussian statistics. It is unclear what causes this statistical anomaly of the negative PDs, but it has been found in both 89 and $166 \mathrm{GHz}$ data, and the anomaly has an interesting geographical distribution. More details on the PD noise determination and the geographical distribution of the negative PDs can be found in Appendix B.

The PD climatology is computed globally and sorted according to latitude, $\mathrm{PD}-\mathrm{TB}_{\mathrm{V}}$, and the PD value itself in $10^{\circ}$, $10 \mathrm{~K}$, and $1 \mathrm{~K}$ bins, respectively. We also compiled a twodimensional (2-D) PDF with respect to PD and PD-TB $\mathrm{V}_{\mathrm{V}}$ for each latitude bin. Monthly statistics of the $\mathrm{PD}-\mathrm{TB}_{\mathrm{V}}$ relationship are characterized by the peak and standard deviation of each 2-D PDF. Only the cloudy-sky portion of the PD$\mathrm{TB}_{\mathrm{V}}$ relationship is reported in this study using the $3 \sigma$ cloud 
detection with the $183.3 \pm 3 \mathrm{GHz}$ radiances in each latitude band and computed separately for land and ocean.

Six months of GMI L1C-R data (June, July, and August in 2014 and 2015) have been compiled to study the cloudysky PD statistics. Although we use an earlier data version (V03) in this study, we find that the results are similar between V03 and V04 and choose to use the V03 data for the rest of the paper. For the CoSSIR $640 \mathrm{GHz}$ PD data, on which the campaign was based in Costa Rica, the statistics will be compared to the GMI data from the $\left[0,10^{\circ}\right] \mathrm{N}$ latitudinal bin.

To study the scattering properties of cloud ice and precipitation-sized frozen particles at 89 and $166 \mathrm{GHz}$, we make use of precipitation measurements from GPM DPR in our analysis. Galligani et al. (2013) found that large $85 \mathrm{GHz}$ PDs of TRMM-TMI were often associated with a melting layer underneath (detected by TRMM-PR), suggesting a strong connection between cloud ice processes and surface precipitation. Thus, we employ the GPM Ku-band radar bright band (BB) flag to evaluate the 89 and $166 \mathrm{GHz} \mathrm{PD}$ properties and their connection to the presence of $\mathrm{BB}$, as $\mathrm{BB}$ is always associated with stratiform precipitation. For this analysis, we first collocate the measurements between the Ku-band radar and the GMI 89 and $166 \mathrm{GHz}$ data, and then tag the BB flag to each GMI measurement. The Kaband radar also produces a product for classifying stratiform and non-stratiform precipitation cases, but the $\mathrm{Ku}$ radar $\mathrm{BB}$ flag is generally considered to be more reliable (Iguchi et al., 2010).

\section{PD-TBv relationship observed by GMI and CoSSIR}

The bell-shaped curve revealed in Fig. 2 is found to be universal for all latitude bins over land and ocean. Figure 3 shows the tropical statistics over land and ocean for July 2014, where the PDF peaks from the cloudy sky produce a similar PD bell curve for both the land and ocean cases. The bell curve has a peak at $\mathrm{TB}_{\mathrm{V}} \sim 220 \mathrm{~K}$ for $89 \mathrm{GHz}$ and $\mathrm{TB}_{\mathrm{V}} \sim 200 \mathrm{~K}$ for $166 \mathrm{GHz}$. Hence, despite the strong surface PD signal at $89 \mathrm{GHz}$, the cloudy-sky PDs are quite similar between the two channels, both exhibiting a bell curve with a PD peak amplitude of $\sim 10 \mathrm{~K}$. Moreover, cloudinduced brightness temperature depression exhibits a similar dynamical range between 100 and $280 \mathrm{~K}$ at the two frequency channels, but the same $\Delta \mathrm{TB}_{\mathrm{V}}$ at 89 and $166 \mathrm{GHz}$ features the scattering of frozen particles from different heights. Compared with $166 \mathrm{GHz}$, the $89 \mathrm{GHz} \mathrm{TBV}_{\mathrm{V}}$ has a narrower dynamic range $(\sim 60 \mathrm{~K})$ before reaching the PD peak for both oceanic and land conditions. This result is consistent with the TMI $85 \mathrm{GHz}$ PD behavior reported by Prigent et al. (2005), but Defer et al. (2014) reported a somewhat smaller PD peak amplitude $(\sim 8 \mathrm{~K})$ at $89 \mathrm{GHz}$ using the MADRAS instrument onboard the Indo-French MeghaTropiques satellite mission. At $166 \mathrm{GHz}$, PD does not reach its peak until about $80 \mathrm{~K}$ colder than the clear-sky radiance.
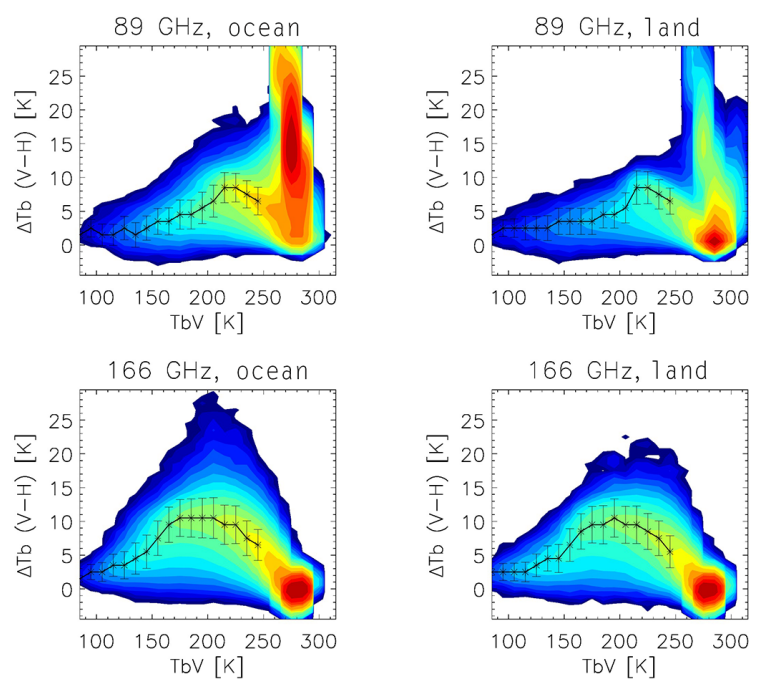

Figure 3. Joint PDFs of $\triangle \mathrm{TB}-\mathrm{TB} \mathrm{V}$ statistics for the $\left[0,10^{\circ}\right] \mathrm{N}$ latitude bin. The GMI $89 \mathrm{GHz}$ (top) and $166 \mathrm{GHz}$ (bottom) data in July 2014-2015 are used in the analysis, but separately for ocean (left) and land (right). Clear-sky data are excluded in computing the PDF peaks, while the cloudy-sky PDF peaks are connected by a black line with the standard deviation of PD shown for each bin. Cloudy sky is determined by the $3 \sigma$ threshold method using the $183 \pm 3 \mathrm{GHz}$ radiances. The color contour for the PDFs is in $\log$ scale.

Besides, the peak amplitude at $166 \mathrm{GHz}$ is slightly larger than that at $89 \mathrm{GHz}$. This finding is consistent with Defer et al. (2014) using MADRAS's $157 \mathrm{GHz}$ polarization channel pairs. The PD bell curve gradually diminishes at clear-sky scenes $\left(\mathrm{TB}_{\mathrm{V}} \sim 280 \mathrm{~K}\right)$, but approaches $\sim+2 \mathrm{~K}$ at very thick convective clouds $\left(\mathrm{TB}_{\mathrm{V}} \sim 100 \mathrm{~K}\right)$. These PD-TBVv features are also evident for synoptic-scale clouds in the mid-latitude (see Figs. $\mathrm{C} 1$ or 4 for examples).

The spatial distribution of cloud occurring frequency (CF) weighted PD (i.e., CF*averaged PD in each grid box) is high over active convective regions (not shown), similar to the $\mathrm{CF}$ from tropical deep convection zones and peaking near the Equator in the summer hemisphere. This distribution shows typical active convective centers (e.g., the central United States in July), as expected for thick anvil outflows from the deep convective cells. The PD-TBV bell curve is seen at latitude bins of up to $50^{\circ} \mathrm{N} / \mathrm{S}$ (Figs. 4 and $\mathrm{C} 1$ ).

Figure 4 summarizes the latitudinal dependence of the bell curves at each $20^{\circ}$ latitude bin over land and ocean, respectively. Six months of data (June, July, and August of 2014 and 2015) are averaged together to increase the statistical robustness. The surface PD branch has been removed using the $183 \mathrm{GHz}$ radiances and the $3 \sigma$ threshold separation for clear-cloudy skies. All the bell curves over the ocean are essentially the same, especially at $30^{\circ} \mathrm{S}-50^{\circ} \mathrm{N}$. The wintertime high-latitude $\left(70-50^{\circ} \mathrm{S}\right)$ belt is an exception. This is also evident at 89 and $166 \mathrm{GHz}$ over land (Fig. 4c, d), which may be associated with the drier atmosphere at high latitudes in 

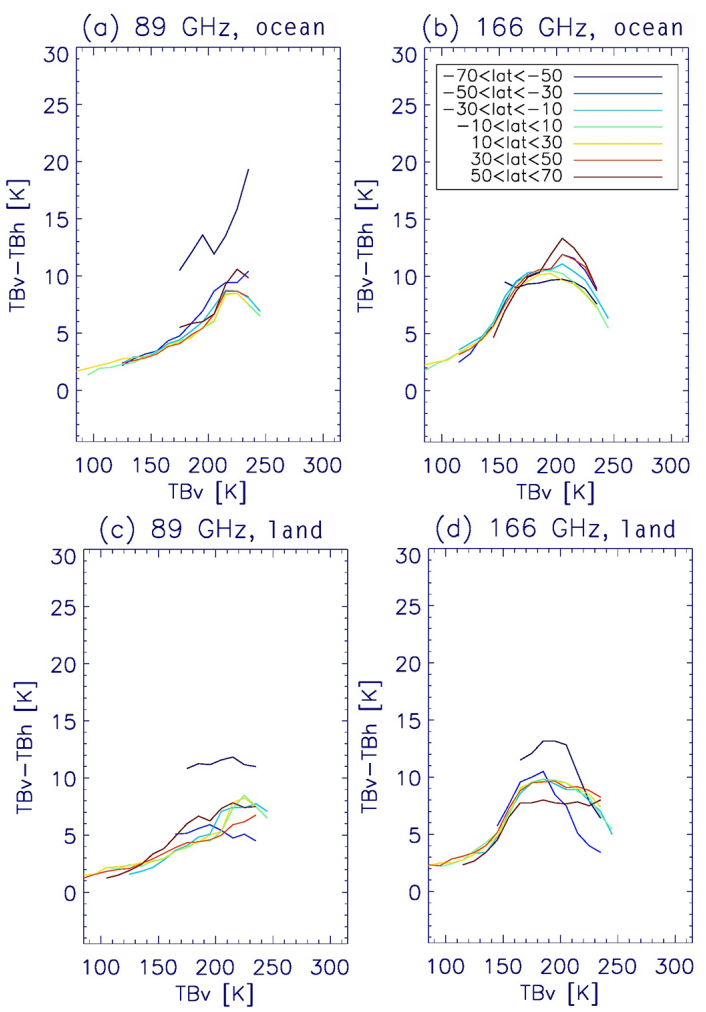

Figure 4. The PDF peak curves from different latitude belts (see label) derived from June-July-August 2014 and 2015 climatologies. Top panels for ocean and bottom panels for land conditions, respectively. The surface signal is removed using the $183.3 \pm 3 \mathrm{GHz}$ radiance and the $3 \sigma$ threshold method.

the winter atmosphere. Although the dynamic range of $\mathrm{TB}_{\mathrm{V}}$ shrinks with increasing latitude, the PD peaks are still detectable and occur at about the same $\mathrm{TB}_{\mathrm{V}}$ value $(\sim 220 \mathrm{~K})$ for the $89 \mathrm{GHz}$ oceanic clouds credited to the large clearsky variability and the resulting $3 \sigma$ threshold. These findings suggest that the ensemble characteristics of the ice crystal shape and orientation that $89 \mathrm{GHz}$ is sensitive to are consistent across all latitudes, which is a piece of good news to both the satellite retrieval and cloud modeling group, as many cloud microphysics assumptions during the retrieval and modeling processes are based on mid-latitude observations. The stringency of shape and orientation parameters ensures less uncertainty in the retrieving/modeling of the tropical and high-latitude atmosphere.

The oceanic $166 \mathrm{GHz}$ PDs at $\mathrm{TB}_{\mathrm{V}}=200-220 \mathrm{~K}$ appear to increase with latitude in both hemispheres (Fig. 4b). There is also a hint in Fig. 4a of $89 \mathrm{GHz}$, although the tendency is rather weak. This latitudinal dependence of the PD amplitude could be due to latitude-dependent water vapor abundance, because ample water vapor can damp the PD signal. The water vapor damping is stronger in the tropics and consequently flattens the $\mathrm{PD}-\mathrm{TB}_{\mathrm{V}}$ curve more. The water vapor attenuation effect is also evident for ocean conditions at mid to high latitudes of the winter atmosphere $\left(30-70^{\circ} \mathrm{S}\right)$, which is caused by the fact that the atmosphere there is very dry and cannot block the surface signal anymore (e.g., Fig. C1d). However, the upper troposphere water vapor amount should be roughly symmetric between the two hemispheres (Solden and Lanzante, 1996), but the PD curves do not suggest such an inter-hemisphere symmetry. Over the ocean, the PD peak amplitude is slightly larger in the summer hemisphere, while it is contrary over land. Therefore, the role of water vapor in attenuating the PD is perhaps more complicated than expected. We will explore this in more detail in the next section.

Studying the CoSSIR $640 \mathrm{GHz}$ measurements from the TC4 campaign, we also find a bell curve in the PD-TBV relationship (Fig. 5). Interestingly, the largest PD amplitude remains at $\sim 10 \mathrm{~K}$, and occurs at $\mathrm{TB}_{\mathrm{V}} \sim 200 \mathrm{~K}$. Some high PDs are found in thin cirrus cloud/clear-sky scenes near $\mathrm{TB}_{\mathrm{V}}=250 \mathrm{~K}$ and in optically thick clouds of $\mathrm{TB}_{\mathrm{V}}=150 \mathrm{~K}$, which are also associated with large negative PD values. These cases are found in the 19 July and 6 August flight legs but not in the 17 July flight leg. Data qualities are considered much noisier in the former two flights than the latter one, but we still keep showing the original data from all three flight legs in Fig. 5 as the peak of the PD-TB $\mathrm{V}_{\mathrm{V}}$ relationship is altered little by including the noisier data (F. Evans, personal communication, 2015).

To summarize, robust and significant PD signals from GMI's 89 and $166 \mathrm{GHz}$ channels contain ample information about the ice microphysics of frozen particles. There exists a universal bell curve in the $\mathrm{PD}-\mathrm{TB}_{\mathrm{V}}$ relationships at all highfrequency microwave channels, including the $640 \mathrm{GHz}$ observations from CoSSIR. They all show a peak amplitude of $\sim 10 \mathrm{~K}$ at $\mathrm{TB}_{\mathrm{V}}=200-220 \mathrm{~K}$. What cause(s) the bell curve is an interesting question for remote sensing microphysical properties (size and shape) of frozen particles. In the next section, we will discuss two plausible mechanisms that may explain the observed features.

\section{Discussions}

\subsection{Radiative transfer models (RTMs) and the concept of the aspect ratio (AR)}

To evaluate impacts of frozen particle orientation and ice water content (IWC) on the $T_{\mathrm{b}}$ and PD-TBV relationship, two numerical RTMs are employed in this study. The first model is called the Polarized Radiative Transfer Model Distribution (PolRadTran) developed by Evans and Stephens (1995). Two options of the scattering solver are included in PolRadTran: RT3 and RT4. While RT3 assumes random orientation, RT4 assumes $100 \%$ horizontal alignment. The solutions are essentially identical for spheroid but not nonspherical particles. In our study, PolRadTran is configured to mimic GMI and CoSSIR's viewing geometry and channel frequencies, and both RT4 and RT3 solvers are employed, 


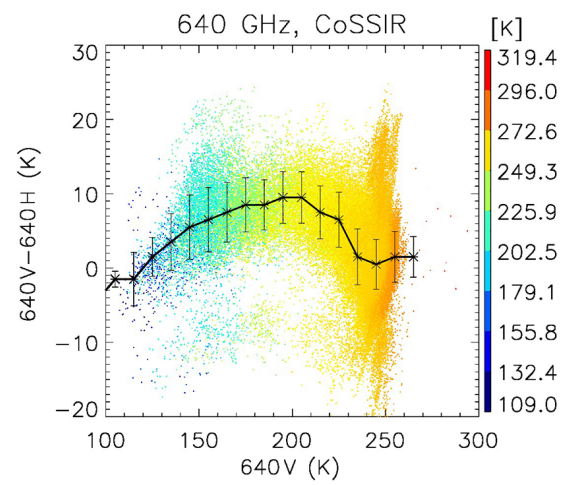

Figure 5. Scatter plot of quality-controlled CoSSIR PD-TBVV $640 \mathrm{GHz}$ measurements from the TC4 campaign. Observations over land and ocean are not separated here. The black solid line with error bars is the PDF peak, where bins beyond $260 \mathrm{~K}$ are excluded because of the sparseness of the data.

assuming several non-spherical ice habits (snowflake dendrites, hexagonal plate, cylindrical columns, bullet rosettes with seven branches). Their scattering properties for diameters ranging from 20 to $2000 \mu \mathrm{m}$ are adapted from Yang et al. (2013), albeit that Yang et al. (2013)'s calculation is only valid for the visible to far-infrared spectrum strictly speaking. As described in Evans and Stephens (1995), the fast Fourier transform (FFT) approach has been used to solve the discrete dipole approximation (DDA) scattering computation rapidly once the ice refractive index is provided. This index has a weak dependence on the ice particle temperature and we used the value at $240 \mathrm{~K}$ in this study. Values at other temperatures $(220,260 \mathrm{~K})$ have also been tested, and only show minor differences in the results. Frozen particles are assumed to obey a Gamma size distribution in general (Evans et al., 2012), which is characterized by the mean mass-weighted equivalent sphere diameter $\left(D_{\mathrm{me}}\right)$. The desired gamma size distribution is achieved using an optimization procedure to adjust the equivalent volume diameter $\left(D_{\mathrm{e}}\right)$, where $D_{\mathrm{me}}=\left\langle D_{\mathrm{e}}^{4}\right\rangle /\left\langle D_{\mathrm{e}}^{3}\right\rangle$. This optimization procedure assures that the truncated and discrete size distribution has the desired moments (i.e., $D_{\text {me }}$ and dispersion width).

The RT4 simulations we carried out in this study assume a uniform ice cloud layer with horizontally oriented nonspherical ice particles in a background atmosphere. Lambertian and Fresnel scatterings are used for land and ocean surfaces, respectively. Input variables are size distribution $\left(D_{\mathrm{me}}\right)$, channel frequency, ice water path (IWP) and cloud layer bottom and top heights. Then, the model computes the $\mathrm{V}$ - and H-pol $T_{\mathrm{b}}$ at the top of atmosphere (TOA) for a set of viewing angles, from which the GMI/CoSSIR TBs are derived by interpolating the model $T_{\mathrm{b}}$ outputs to their viewing angles.

The RT3 option of the PolRadTran model will also be employed to reveal the radiation behavior of a medium of randomly oriented particles. Different from RT4, which only considers the thermal radiation, RT3 includes the solar radiation as well. But for our purpose on the microwave spectrum, solar radiation is negligible.

The RT4 model and the configuration of our simulations have several limitations. Firstly, PolRadTran is not a fully polarized RTM, strictly speaking. Plane-parallel, horizontally homogeneous, and azimuthally symmetric orientation is assumed for PolRadTran and RT4, such that we only need to calculate two out of the four Stokes parameters, while the other two remain zero. The modeled ice crystal shapes (except dendrites) represent primarily the pristine mid-latitude cirrus from synoptic outflows, which is not ideal for larger ice particles in the stratiform precipitating regions nor for tropical deep convection cases. The ice particle scattering properties were adapted from Yang et al. (2013), where the calculations stop at far-infrared. In the future, a more suitable database, e.g., Liu (2008), might be employed to replace the current input database. While the DDA calculation is very efficient for computing cirrus particle scattering, it is still computationally expensive for large particles, of which the valid range of IWP is limited to $<1 \mathrm{~kg} \mathrm{~m}^{-2}$ and $D_{\mathrm{me}}$ to $<500 \mu \mathrm{m}$. Besides, the RT4 surface model and homogeneous ice cloud layers are often over-simplified compared to the reality. Because of these limitations, RT4 is perhaps mostly suitable for simulating the $640 \mathrm{GHz}$ PDs where the surface contributes the least, compared to the lower-frequency channels, and this channel is insensitive to precipitation-sized ice particles. Assuming random particle orientation, Evans et al. (2012) applied the RT4 model with a dynamical mixture of different particle shapes to cloud ice retrievals on the CoSSIR data.

Another RTM for simulating frozen particle scattering, called the Cloud Radiance Model (CRM), is based on the cloudy-sky forward model in the Aura Microwave Limb Sounder (MLS) (Wu and Jiang, 2004; Gong and Wu, 2014). The CRM is a non-polarized model, and it assumes only spherical ice particles in the scattering calculation. It has been applied to simulate cloud-induced radiances at frequencies $<3 \mathrm{THz}$ for a complicated viewing geometry (e.g., satellite nadir/limb sounding, in-cloud aircraft flight, and ground stations). Like RT4, CRM assumes the Gamma size distribution in the current study. Different from RT4, CRM allows the user to specify the vertical distribution of IWC or liquid water content (LWC) in the mixed-phase case, to study the sensitivity of the cloud-induced radiance to cloud layer height. Cloud height is another free parameter in addition to particle size and IWP, which can alter the cloud radiance amplitude significantly in a similar frequency range (Gong and $\mathrm{Wu}, 2014)$.

To study the effect of frozen particle orientation with CRM, we assume slightly different profiles of scattering volume coefficients at V- and H-pol and $\tau_{\mathrm{V}}(z)$ and $\tau_{\mathrm{H}}(z)$, respectively. The difference is characterized by the aspect ratio (AR) factor, defined as $\mathrm{AR} \equiv \tau_{\mathrm{H}}(z) / \tau_{\mathrm{V}}(z)$, which is assumed to be independent of height. As one can see from the definition, AR is a function of all microphysical properties that 
play a role in determining the optical depth along the line-ofsight (LOS), including particle size, orientation, habit, and density. Only by assuming all other ice microphysical parameters are homogeneous along the LOS can we claim that AR directly corresponds to the axial ratio of the major and minor axes of the ice particle projected to the LOS. The definition of AR is analogous to the "dichroism factor", but the geomagnetic field is believed to play the deterministic role for the latter (Mishchenko, 1991; Mishchenko et al., 2002; Yang et al., 2011). In simulating the PD-TB $\mathrm{V}_{\mathrm{V}}$ relationship, we vary the $\mathrm{AR}$ value but keep the remaining model input parameters (e.g., $D_{\text {me }}$, IWC profile) unchanged. This is equivalent to the particle AR effect in which horizontally oriented particles tend to create a stronger scattering for the H-pol radiation than for the V-pol. Thus, we carry out two parallel simulations with different cloud scattering coefficients but identical settings for other parameters. We then associate the two simulations with the $\mathrm{V}$ - and $\mathrm{H}$-pol cases to evaluate their differences or PD as would be observed by satellite/aircraft at a slant-viewing angle. Using this CRM approach, we will also be able to study the environmental effect on the expected PD as a function of water vapor attenuation in the atmosphere.

In the next section, we will proceed with the model explanation from an extremely simplified two-layer model. By computing the layer-by-layer radiative transfer by including the AR concept, we can reproduce the bell curve with a reasonable range of PD values. Then, the more sophisticated RTMs described above will be employed for further simulating and understanding the observed $\mathrm{PD}-\mathrm{TB}_{\mathrm{V}}$ characteristics.

\subsection{A simple model for the PD-TBV relationship}

The leading hypothesis of the observed positive PD in cloudy sky is that the bulk ice properties produce different volume scattering coefficients in the $\mathrm{V}$ - and $\mathrm{H}$-polarization. The bulk volume scattering coefficients can differ between the V-and $\mathrm{H}$-polarization, depending on ice crystal shapes and their orientation. While the bulk scattering effects of cloud particles are detectable, details about how particles of various shapes organize themselves inside a cloud are beyond the capability of current remote sensing techniques. Clouds may produce little or no PD if the shaped particles are randomly oriented (e.g., tumbling in a turbulent environment). On the other hand, as discussed below, the PD tends to decrease with cloud optical thickness as a result of cloud self-extinction in the radiative transfer.

Let us assume that frozen particles are horizontally aligned, and that the $\mathrm{V}$ - and $\mathrm{H}$-pol extinction coefficients are dominated by scattering. Naturally V- and H-pol radiances pass through the same cloud with slightly different optical depths $\left(\tau_{\mathrm{V}}\right.$ and $\left.\tau_{\mathrm{H}}\right)$. We define the aspect ratio (AR) factor as $\mathrm{AR} \equiv \tau_{\mathrm{H}} / \tau_{\mathrm{V}}$ to characterize this optical depth difference. Figure 6 illustrates a simple two-layer model, where cloud optical depth is $\tau_{2}$. Neglecting the water vapor attenuation,

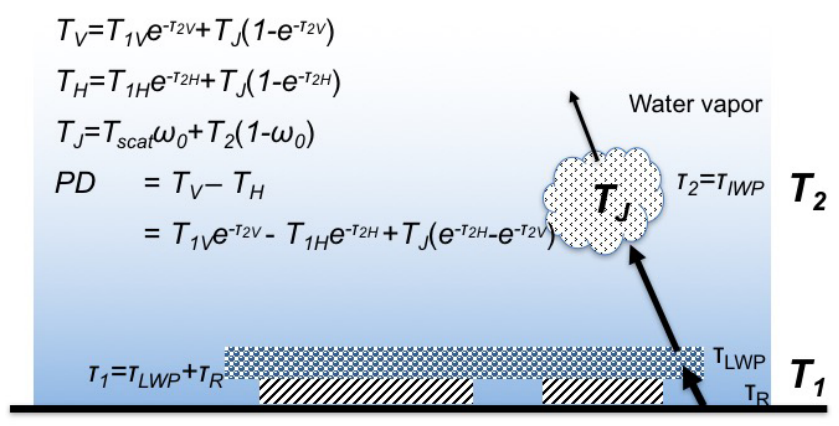

Figure 6. Schematic two-layer model with a liquid/rain/surface layer at $T_{1}$ and an ice cloud layer at $T_{2}$ to explain the observed bell curve in the PD-TBV relationship. See the text for more details and a definition of the variables.

radiance at the TOA can be expressed analytically as

$\mathrm{TB}_{\mathrm{V}}=T_{1 \mathrm{~V}} e^{-\tau_{2 \mathrm{~V}}}+T_{J}\left(1-e^{-\tau_{2 \mathrm{~V}}}\right)$,
$\mathrm{TB}_{\mathrm{H}}=T_{1 \mathrm{H}} e^{-\tau_{2 \mathrm{H}}}+T_{J}\left(1-e^{-\tau_{2 \mathrm{H}}}\right)$,

where $T_{J}$ is the cloud source function, and $T_{1 \mathrm{~V}}$ and $T_{1 \mathrm{H}}$ are the polarized radiances from the background below the cloud resulting from the combination effect of surface, rain, or liquid cloud emissions. The cloud source function $T_{J}=$ $\omega_{0} \times T_{\text {scat }}+\left(1-\omega_{0}\right) \times T_{2}$ contains cloud emission $\left(1-\omega_{0}\right) \times T_{2}$ and scattering $\omega_{0} \times T_{\text {scat }}$ contributions, where $\omega_{0}$ is single scattering albedo and $T_{2}$ is the cloud emission at local air temperature. $T_{\text {scat }}$ is the radiance scattered by clouds into the field of view, a result of the scattering phase function convolved with surrounding radiation, which is approximately half of the upwelling radiation if the downwelling radiation is very small (Wu and Jiang, 2004). The factor $\left(1-e^{-\tau_{2}}\right)$ takes into account the self-extinction process that is intrinsic to any source function in the radiative transfer. In the case that the background emission is unpolarized, i.e., $T_{1 \mathrm{~V}}=T_{1 \mathrm{H}}=T_{1}$, then from Eqs. (1) to (2) we have

$\mathrm{PD}=\mathrm{TB}_{\mathrm{V}}-\mathrm{TB}_{\mathrm{H}}=\left(T_{1}-T_{J}\right)\left(e^{-\tau_{2 \mathrm{~V}}}-e^{-\tau_{2 \mathrm{H}}}\right)$.

This simple two-layer model (Eq. 3 ) is able to reproduce several fundamental features of the observed $\mathrm{PD}-\mathrm{TB}_{\mathrm{V}}$ relationship. As shown in Fig. 7a, it predicts the bell curve as seen in the GMI and CoSSIR polarimetric measurements, showing small PDs at both small and large cloud optical depths or, respectively, warm and cold TBs. At large optical depths, as implied by Eq. (3), the PD diminishes. At small optical depths, Eq. (3) can be approximately written as

$\mathrm{PD}=\left(T_{1}-T_{J}\right)\left(\tau_{2 \mathrm{H}}-\tau_{2 \mathrm{~V}}\right)$.

Because $T_{1}-T_{J}$ is roughly constant according to the observation shown in Fig. 3 in the tropics, this linear dependence on $\tau_{2 \mathrm{H}}-\tau_{2 \mathrm{~V}}$ helps to spread the slopes for different ARs because $\tau_{2 \mathrm{H}}-\tau_{2 \mathrm{~V}}=(\mathrm{AR}-1) \tau_{2 \mathrm{~V}}$. The model can also explain 

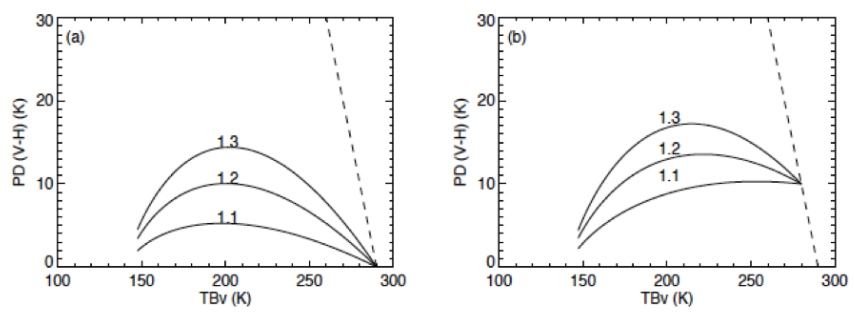

Figure 7. $\mathrm{PD}-\mathrm{TB}_{\mathrm{V}}$ relationships from Eqs. (1) to (2) for different aspect ratios (ARs, value marked above each curve), assuming that the background emission is unpolarized (left, $T_{1 \mathrm{~V}}^{\prime}-T_{1 \mathrm{H}}^{\prime}=0$ ) and polarized (right, $T_{1 \mathrm{~V}}^{\prime}-T_{1 \mathrm{H}}^{\prime}=10 \mathrm{~K}$ ). The dashed line indicates a typically polarized surface emission from wind-induced surface roughness.

the complex $\mathrm{PD}-\mathrm{TB}_{\mathrm{V}}$ relationships seen in the GMI oceanic data where the background surface emission is polarized. Because the $89 \mathrm{GHz}$ channel is more sensitive to the polarized surface emission than the $166 \mathrm{GHz}$, the observed cloud PD often contains both surface and frozen particle contributions. As shown in Fig. 7b, the combined PD from the surface and cloud scattering can result in a tilted bell curve. The observed PD statistics in Fig. 3 are likely a mixture of the two cases shown in Fig. 7.

Finally, the conceptual model predicts weak dependence on channel frequency for the $\mathrm{PD}-\mathrm{TB}_{\mathrm{V}}$ relationship. The reason is as follows. If cloud extinction is dominated by scattering, $\tau$ is proportional to the fourth order of the frequency, i.e., $\tau=\alpha f^{4}$. Therefore, AR is independent of frequency by definition. If the background emission is unpolarized (i.e., $\left.T_{1 \mathrm{~V}}^{\prime}=T_{1 \mathrm{H}}^{\prime}=T_{1}\right)$, the PD from Eqs. (1) to (2) has a maximum of $\left(T_{1}-T_{2}\right)\left(e^{-\tau_{2 \mathrm{~V}}}-e^{-\mathrm{AR} \times \tau_{2 \mathrm{~V}}}\right)$ at $\tau_{2 \mathrm{~V}}=\ln (\mathrm{AR}) /(\mathrm{AR}-1)$, which is only weakly dependent on frequency. This weak dependence of PD on frequency seems to be consistent with the observations that PD amplitudes barely increase from 89 , 166 , to $640 \mathrm{GHz}$.

Radiative transfer in this conceptual model is highly simplified. Although it greatly facilitates our understanding of the bell-curve feature of the $\mathrm{PD}-\mathrm{TB}_{\mathrm{V}}$ relationship, it does not necessarily yield any information about ice microphysical parameters, and hence is not very useful for the development of retrieval algorithms. In order to test whether this theory works in more realistic situations, and more importantly, in order to identify parameters that contribute and are sensitive to the $\mathrm{PD}-\mathrm{TB}_{\mathrm{V}}$ relationship to shed light on future retrieval algorithm development, we further test the AR values of 1.2, 1.3 and 1.4 using the non-polarized CRM. This model is detailed in Wu and Jiang (2004). To simulate polarized radiances, the CRM is run twice: one with the regular cloud extinction profile and one with the regular profile multiplied by AR. The two simulated radiances are differenced to yield the PD as a function of AR. The surface temperature is set to $300 \mathrm{~K}$ in all simulations. The vertical distribution of IWC is assumed as a typical deep convective cloud profile with an anvil top (see Wu and Jiang, 2004, for a description), where the cloud bottom is $5 \mathrm{~km}$ (right above the freezing level in the tropics) and the top at $13 \mathrm{~km}$. Surface polarization is neglected in the simulations. A standard tropical atmosphere is used as the clear-sky background, and hence effects of the water vapor attenuation are included. Gamma distribution is used for ice particles with $D_{\mathrm{me}}=200 \mu \mathrm{m}$. This large value takes into account a mixture of cloud and precipitation particles such that large $T_{\mathrm{b}}$ depression can be produced. Other $D_{\text {me }}$ values have also been tested. While the dynamic range of $T_{\mathrm{b}}$ is sensitive to $D_{\text {me }}$, the peak PD amplitude is not. In the simulations only IWP is varied to create the $\mathrm{PD}-\mathrm{TB}_{\mathrm{V}}$ curves that best mimic the observations.

Although the AR in the range of $[1.2,1.4]$ produces a good envelope for the observed bell curves, $\mathrm{AR}=1.3$ seems to fit best overall to the observations. This AR value was also found in Davis et al. (2005) in studying the $122 \mathrm{GHz}$ data, but the AR defined in that paper has a direct microphysical meaning of particle axial ratio. Having said that, there is an indication that the best fit of the AR might increase with frequency, suggesting an increasing contribution of horizontally oriented particles at higher frequencies. Since the higher frequencies are more sensitive to small frozen particles, it implies that small frozen particles have an increased percentage of the horizontal orientation. While it is difficult to infer the detailed composition of particle habits in these clouds, ice crystals in cirrus clouds (more sensitive by $640 \mathrm{GHz}$ ) are likely to have a predominant type (e.g., plate, column; Libbrecht, 2005), and snow aggregates (more sensitive by $89 \mathrm{GHz}$ ) tend to have diverse irregular shapes. In addition, the ambient air in the upper troposphere anvils and cirrus (where the $640 \mathrm{GHz}$ weighting function peaks) is likely more stable than the tumbling environment inside deep convective cores (where the $89 \mathrm{GHz}$ weighting function peaks). Therefore, a higher degree of alignment of non-spherical particles in the anvils/cirrus could also contribute to the larger AR value at $640 \mathrm{GHz}$. This possibility will be elaborated further at the end of Sect. 4.3. The third possible explanation involves the water vapor attenuation effect. Although all three frequencies are window channels, they are still affected by water vapor abundance. But as found previously in Gong and $\mathrm{Wu}$ (2014), the water vapor attenuation effect is minor when cloud is present. The last plausible explanation of why the simulated $640 \mathrm{GHz}$ peak amplitude is weaker than that of the other two frequencies with the same AR value originates from the background atmosphere lapse rate change. As the atmosphere becomes more isothermal approaching the tropopause, the differentiation between the slightly higher weighting function (WF) of the V-pol compared to that of the H-pol starts to diminish accordingly, resulting in smaller $\mathrm{PD}$ at $640 \mathrm{GHz}$ as its WF peak centers at the upper troposphere. Although the simulated behavior of the peak amplitude change with frequency is likely for the above reason, the observed peak amplitude at $640 \mathrm{GHz}$ is not discernably weaker than the other two frequencies. As one can always 

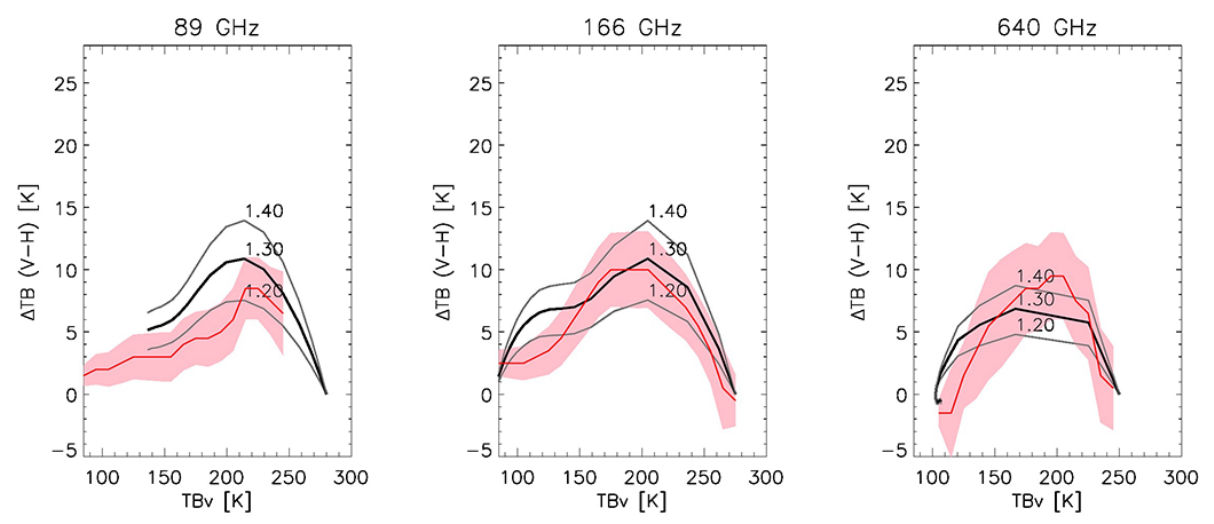

Figure 8. CRM simulated PD-TBV curves in black for AR values of 1.2, 1.4, (thin) and 1.3 (bold), overlaid on top of the GMI and CoSSIR observations in red for (a) 89, (b) 166, and (c) $640 \mathrm{GHz}$ with the standard deviation shown in pink shades. Surface contaminations are removed using the cloud flag derived from the $183.3 \pm 3 \mathrm{GHz}$ channel.

argue that this might be due to limited sample size for the $640 \mathrm{GHz}$ measurements, including more $640 \mathrm{GHz}$ observations in the analysis is indeed the only way to solve the puzzle.

\subsection{Horizontally polarized model simulation}

AR is a parameter that characterizes the collective scattering property of frozen particle habits. To study the relative importance of individual particle habits, we use a horizontally polarized RT4, a variant of the PolTranRad model (Evans and Stephens, 1995), to simulate the PD-TBV relationship. Four types of ice habits and different $D_{\text {me }}$ are used in the simulations, and the results are shown in Fig. 9 for $640 \mathrm{GHz}$ assuming all frozen particles are horizontally aligned. As seen in Fig. 9, snowflake dendrites and cylindrical columns are most effective shapes to produce large PD values at $640 \mathrm{GHz}$, whereas cylindrical columns and bullet rosettes can also induce a similar PD amplitude to what is measured by CoSSIR. The first two ice crystal types result in excessively large PDs in the PD-TBV relationship. For bullet rosettes, on the other hand, the PD does not produce the bell curve when the cloud becomes optically thick, whereas the cylindrical column shaped crystal with $D_{\text {me }}$ between 200 and $300 \mu \mathrm{m}$ produces the best agreement with the observation. According to Yang et al. (2013), this type of ice crystal with $D_{\mathrm{me}}=250 \mu \mathrm{m}$, when projected to the GMI's viewing direction, has an AR of 1.46, a value in surprisingly good agreement with that from the CRM simulations shown in Fig. 8c. This consistency also supports the AR values used in the simple conceptual model and its radiative transfer argument for the bell-shape curve. We hope with more accurate multifrequency polarimetric measurements that ice habits may be retrievable from the $\mathrm{PD}-\mathrm{TB}_{\mathrm{V}}$ relationship eventually. More questions also arise. For example, given that ice crystals have a vast variety of shapes in reality, why are the $\mathrm{PD}-\mathrm{TB}_{\mathrm{V}}$ relationships at $640 \mathrm{GHz}$ similar to those at lower-frequency
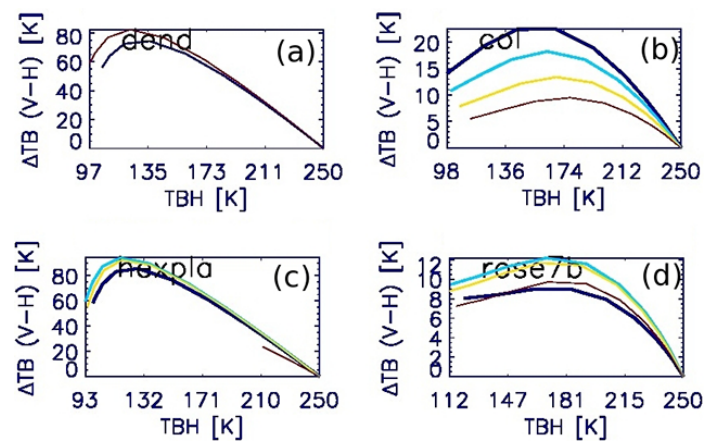

Figure 9. PolTranRad simulations of the $640 \mathrm{GHz}$ PD-TBV relationship for four different ice habits: (a) snowflake dendrite, (b) hexagonal plate, (c) cylindrical column, and (d) bullet rosette with seven branches. All frozen particles are assumed to be horizontally aligned. The red and blue in the snowflake dendrite simulation correspond to $D_{\mathrm{me}}=200$ and $300 \mu \mathrm{m}$, respectively. In the remaining panels, red, yellow, cyan, and blue denote $D_{\mathrm{me}}=200$, 300,400 , and $500 \mu \mathrm{m}$, respectively.

channels? Future field campaigns with polarimetric measurements from higher-frequency channels should provide more insightful information to address similar questions.

One of the top questions investigated in this study is the following: what process causes the low PDs of the bell curve at cold TBs? One could argue that at cold TBs (i.e., strongly depressed by the scattering of deep convective clouds) the orientations of frozen particles were mostly random instead of horizontally aligned. As a result, those deep convective cold $T_{\mathrm{b}}$ cases would yield a weaker PD. PolTranRad has another version called RT3, which allows one to simulate effects from randomly orientated ice crystals, and the bell curve is found to be still present, despite the amplitude being rather small $(<3 \mathrm{~K})$ regardless of the type of ice habit used. Thus, the random orientation of frozen particles does 
not completely cancel out the particle shape effects, as revealed by the RT3 simulations.

A varying mixture of randomly and horizontally oriented particles may also provide a plausible explanation of the observed bell curve. If the larger mixing factor " $\alpha$ " corresponds to a more mixed environment inside clouds, $\alpha$ is likely to increase with deep convection strength or a colder $T_{\mathrm{b}}$. On the other hand, horizontally aligned non-spherical particles are likely more effective to produce PDs in the anvil outflows than convective cores, because random orientation within the turbulent convective core tends to cancel out the PD. This mechanism seems to have a support evidence in the groundbased Doppler radar observations (Homeyer and Kumjian, 2015), where they often found lower differential reflectivity (ZDR) near the deep convective core but larger values in the anvil outflows. In addition, the irregular shape of graupel found near convective cores likely contributes to a small PD as well, as suggested in their paper.

\subsection{PDs from melting layers and ice clouds}

Since 89 and $166 \mathrm{GHz}$ radiances are sensitive to scattering and emission of the precipitation-sized frozen particles, we need also to take into account the effects of the floating snow layer (Xie et al., 2012) or the melting layer close to the surface (Galligani et al., 2013) underneath the cloud layer. Although it is difficult to quantify the PD sensitivity separately for different layers of frozen particles, it is possible to evaluate the response of PD to the melting layer with the combined DPR-GMI observations. Melting layers manifest themselves as a unique bright band (BB) on the $\mathrm{Ku}$-band radar reflectivity profile, as a result of stratiform rainfall. We therefore use the BB flag and precipitation flag in DPR's $\mathrm{Ku}$ band radar Level-2 products to discriminate the stratiform and non-stratiform precipitation scenes. Non-stratiform precipitation types include convective rainfall and snowfall.

Figure 10a shows a joint 89 and $166 \mathrm{GHz}$ PD PDF with rather diverse relationships for oceanic measurements with and without BB. There are two branches in the 89 and $166 \mathrm{GHz}$ PD correlation characterized by different slopes: $1: 2$ and $4: 1$. The measurements in the $4: 1$ slope are dominated by the polarized ocean surface emission, whereas the $1: 2$ group has little contributions from the surface. Because the $1: 2$ branch over the ocean is also associated with the strongly polarized ocean surface, it should be related to lightly precipitating scenes that otherwise would show much stronger PD signals. In the case with $\mathrm{BB}$, most of the polarized surface emission is blocked by BB. For non-stratiform precipitation (without $\mathrm{BB}$ ), most likely there will be no $\mathrm{PD}$ signal from both channels (i.e., the center of the black contours is near the origin point in Fig. 10a). This indicates that the dominant PD signals of 89 and $166 \mathrm{GHz}$ indeed come from ice cloud for non-stratiform precipitation, even if it is snowfall when the snow scattering is relatively weak at $89 \mathrm{GHz}$, which makes it capable of "seeing" the surface in
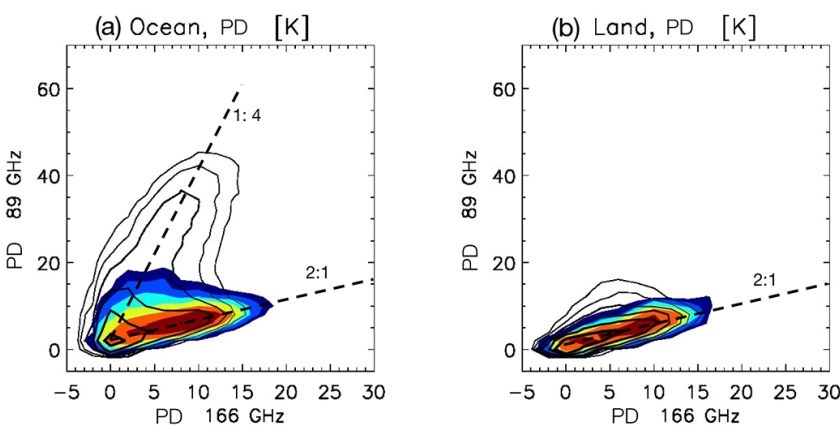

Figure 10. Joint PDF of 89 and $166 \mathrm{GHz}$ PDs during January 2015 over the (a) ocean and (b) land for precipitation with the bright band (color shaded) and without the bright band (black contours). Color and contours are normalized such that the total areas equal unity, and are plotted in log scale.

this case. When the melting layer is present, both 89 and $166 \mathrm{GHz}$ PDs incline to be positive. As a result, when the melting layer is present, the peak of the joint PDF (dark red) moves to $\sim 5$ and $8 \mathrm{~K}$ for 89 and $166 \mathrm{GHz}$, respectively, as shown by the color shades in Fig. 10a, implying that the melting layer in fact contributes partially to the PD signal. This finding is consistent with Galligani et al. (2013), where they found that the $85 \mathrm{GHz}$ PD of TRMM's TMI is likely positive when the melting layer is present. It is also consistent with the higher BB ZDR as observed by ground-based radars (e.g., Oue et al., 2015). While $166 \mathrm{GHz}$ is more sensitive to smaller ice crystals than $89 \mathrm{GHz}$, the more positive PD response in the $166 \mathrm{GHz}$ indicates that smaller ice crystals should be more obsolete and/or more horizontally oriented. Larger particles like snow aggregates likely exhibit irregular shapes and the scattering signal in $89 \mathrm{GHz}$ would hence be less directional, resulting in a smaller PD response in this channel. This finding is highly consistent with the weak increase in the AR value with the increase in channel frequency in CRM simulations shown in Sect. 4.2. Moreover, frozen particles of all sizes tend to be more horizontally oriented for stratiform rainfall compared with non-stratiform precipitation (Houze, 2014; Sect. 6.2)

Over land, the PD characteristics vary roughly the same way as those over the ocean, but the $4: 1$ branch exhibited in the ocean case is not present in the land non-stratiform precipitation cases. The PDF peaks along the $1: 2$ line are different in the cases with and without BB. Other factors, e.g., liquid emission, may also play a non-trivial role here, but they are hard to justify at this moment. Due to the complexity of the melting layer, this paper does not intend to further quantify its role in the PD's characteristics.

\section{Conclusion and future work}

High-frequency microwave polarimetric measurements contain ample information of frozen particle habit and orienta- 
tion. In this paper, the GMI 89 and $166 \mathrm{GHz}$ PD characteristics are analyzed, which reveal a universal bell curve in the $\mathrm{PD}-\mathrm{TB}_{\mathrm{V}}$ relationship. The bell curve also exists in the CoSSIR $640 \mathrm{GHz}$ observations. All three frequency channels show a maximum PD amplitude of $\sim 10 \mathrm{~K}$, occurring around $T_{\mathrm{b}}=200-220 \mathrm{~K}$. Such a PD-TB $\mathrm{V}$ relationship is robust for almost all frequencies and latitudes. Moreover, both 89 and $166 \mathrm{GHz}$ channels show positive PD responses when a melting layer is present. This is a new feature not reported before, suggesting that at least part of the PD signals comes from the melting layer. The melting layer contribution is confirmed by comparing the PD statistics with non-stratiform precipitation situations.

Using a simple analytical radiative transfer model, we can explain the bell curve of the $\mathrm{PD}-\mathrm{TB}_{\mathrm{V}}$ relationship with the term of the aspect ratio (AR). In this simple model we assume that the V- and H-pol extinction coefficient profiles are similar and scaled by AR. According to this conceptual model, the PD results from the stronger extinction at the H-pol, but diminishes as the cloud scattering is too strong to become saturated to a constant $T_{\mathrm{b}}$ in both polarizations. In addition, a fully polarized RTM is employed to study the effects of the frozen particle habit and orientation on the PD. The mixing of different particle habits and orientations inside deep convections break down the directional orientation, which cancels out the non-spherical shape effect, which can result in a bell curve in the $\mathrm{PD}-\mathrm{TB}_{\mathrm{V}}$ relationship.

Our fully polarized RTM simulations suggest a strong sensitivity of the PD's magnitude to ice habit at $640 \mathrm{GHz}$, i.e., the shape factor. Previous research (Defer et al., 2014) using another fully polarized RTM also recognized that other ice microphysical properties, including density and size, would impact the simulation results seriously. Therefore, more observations from higher-frequency microwave or even IR channels are very much needed, and would greatly facilitate the decoding of the microphysical information of frozen particle shape and orientation at different portions of the crystal size spectrum.
Negative PD values are also found in these polarimetric measurements. The spatial distribution of the negative PDs does not coincide with the most active convection regions. Although they have been hypothesized as a result of vertically oriented frozen particles, careful consideration of measurement noise and surface properties is required before being interpreted as a result of particle properties. The ample information embedded in PD sheds light on the future path of retrieval method development of more frozen particle microphysical properties.

Last but not least, the observed $\mathrm{PD}-\mathrm{TB}_{\mathrm{V}}$ relationship has an important implication for cloud ice retrieval. Gong and Wu (2014) used an empirical IW-TB relationship derived from CloudSat-MHS (Microwave Humidity Sounder) measurements for the IWP retrieval, where they found this relationship is nearly linear for medium thick ice cloud (i.e., anvils). The observed PD value range in this study therefore can be translated into a 30\% IWP retrieval error if polarization is neglected. This is a very rough estimate that warrants a thorough evaluation in the future.

\section{Data availability}

The GMI Level 1 calibrated radiance data are available for download at https://disc.gsfc.nasa.gov/datareleases/gpm gmi_Level_1_data_release. CoSSIR data from the TC4 campaign are available at https://atmospheres.gsfc.nasa.gov/ meso/index.php?section=122. PolTranRad can be pursued at http://nit.colorado.edu/polrad.html. CRM is coded and modified by the authors for this study and is not intended for public distribution. Interested readers are encouraged to contact the authors directly for a copy. 
Appendix A: Mismatch and re-collocation of GMI lowand high-frequency channel measurements

Figure A1 illustrates the necessity of using L1C-R data to screen out the 89 and $166 \mathrm{GHz}$ clear-sky scenes. Compared to the L1B dataset that does not collocate the LF and HF channels, the $183.3 \pm 3 \mathrm{GHz} T_{\mathrm{b}}$ now corresponds much better to the $89 \mathrm{GHz} T_{\mathrm{b}}$. Moreover, the 166 and $89 \mathrm{GHz} \mathrm{TBs}$ show much better coherence in the L1C-R data, showing two separate branches more clearly in Fig. A1d. The different slopes of these two branches correspond to the clear-sky and cloudy-sky characteristics, respectively, and the clearsky branch is also warmest in the $183.3 \pm 3 \mathrm{GHz} T_{\mathrm{b}}$. The scatter behavior of Fig. A1d is very similar to the comparable instrument, e.g., the Special Sensor Microwave Imager and Sounder's 91 and $150 \mathrm{GHz}$ channels (not shown).
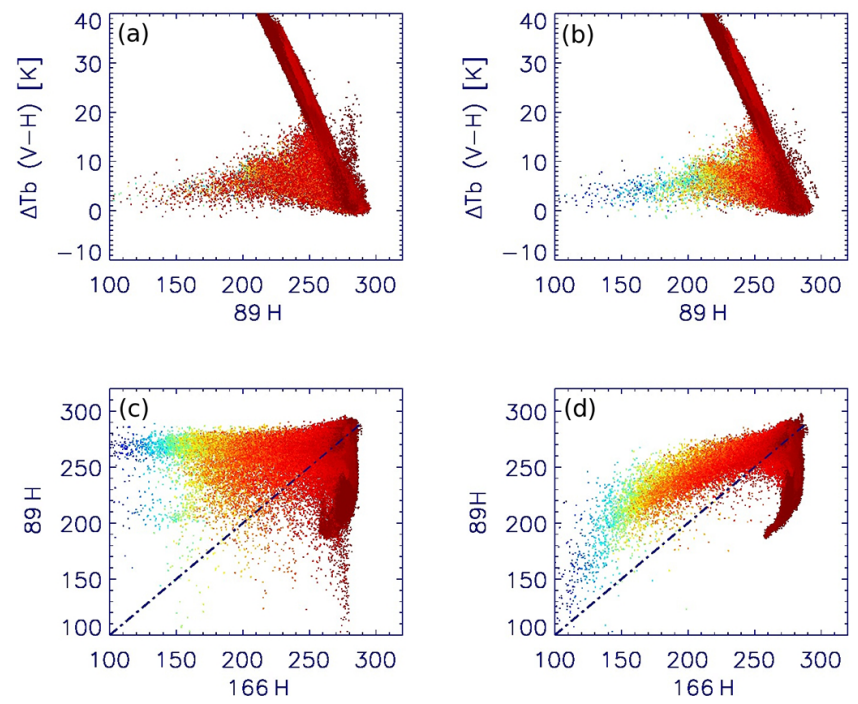

Figure A1. Scatter plots of 1-day tropical oceanic radiance measurements from the L1B (a, c) and L1C-R (b, d) datasets, showing poorly (L1B) and correctly (L1C-R) georegistered radiance data. Points are color-coded by the $183.3 \pm 3 \mathrm{GHz}$ radiance values, with red being warm and blue being cold.

\section{Appendix B: Estimation of instrument noise and distribution of negative $P D$}

The GMI's 89 and $166 \mathrm{GHz}$ PDs are not always positive. As a matter of fact, negative values occur frequently, and their occurrence is independent of the $T_{\mathrm{b}}$. However, a large negative PD only happens occasionally. The histogram of a negative PD closely follows the Gaussian distribution, as shown in Fig. B1 by the black solid fitted lines. The "Gaussian_fit" function from the IDL software package is used for this purpose, where the mean $(\mu)$ and standard deviation $(\sigma)$ parameters are given as output. The standard deviation of the fitted Gaussian curve is a good estimate of the instrument noise (e.g., Wu et al., 2009). Following the same analogy, we define the standard deviation parameter from the fitted Gaussian distribution as the GMI's instrument noise. $\sigma$ is computed consequently for 2 months of 2015, January and July, for each $10^{\circ}$ latitude belt, which varies limitedly among different latitudes, surface conditions and seasons. The averaged $\sigma$ is about $0.5 \mathrm{~K}$ for $89 \mathrm{GHz}$ and $1 \mathrm{~K}$ for $166 \mathrm{GHz}$. Note that the radiance noise level should be derived by dividing $\sigma$ by $\sqrt{2}$.

If the negative PDs purely originate from instrument noise, they should be randomly distributed geographically. However, that is not the case for $166 \mathrm{GHz}$. If we plot out the occurrence frequency $(\mathrm{OF})$ map of negative PDs that are smaller than the negative instrument noise estimated using the aforementioned method, the $\mathrm{OF}$ is trivial at $89 \mathrm{GHz}$, indicating that negative PD is likely instrument noise. But for $166 \mathrm{GHz}$, large negative PDs occur quite frequently (up to $18 \%$ of the time), and they seem to favor the winter-hemisphere side of the tropical deep convections, as shown by Fig. B2. This is the first time such a geographical preference has ever been reported.

One theory explains the negative PD as the scattering effect from predominantly vertically oriented ice crystals that may be oriented by the electromagnetic field created by lightning near the cloud top (Prigent et al., 2005; Homeyer and Kumjian, 2015). We can also consider the vertical orientation a counterpart solution of the horizontal orientation from the RTMs, as the latter can only produce positive PD signals. However, global lightning distribution, which essentially connects to the tropical deep convective activities, correlates poorly with the geographic distribution of negative PDs (e.g., Cecil et al., 2014). Instrument noise is not likely the underlying cause of $166 \mathrm{GHz}$ either, since it would be randomly distributed otherwise. Having said that, the secondary branch in the negative PD branch in Fig. 4 surely generated more interest in studying the causes of negative PDs. Although the actual cause remains unclear at this moment, negative PDs, especially the large magnitude one, ensure a rather attractive topic for future studies. 

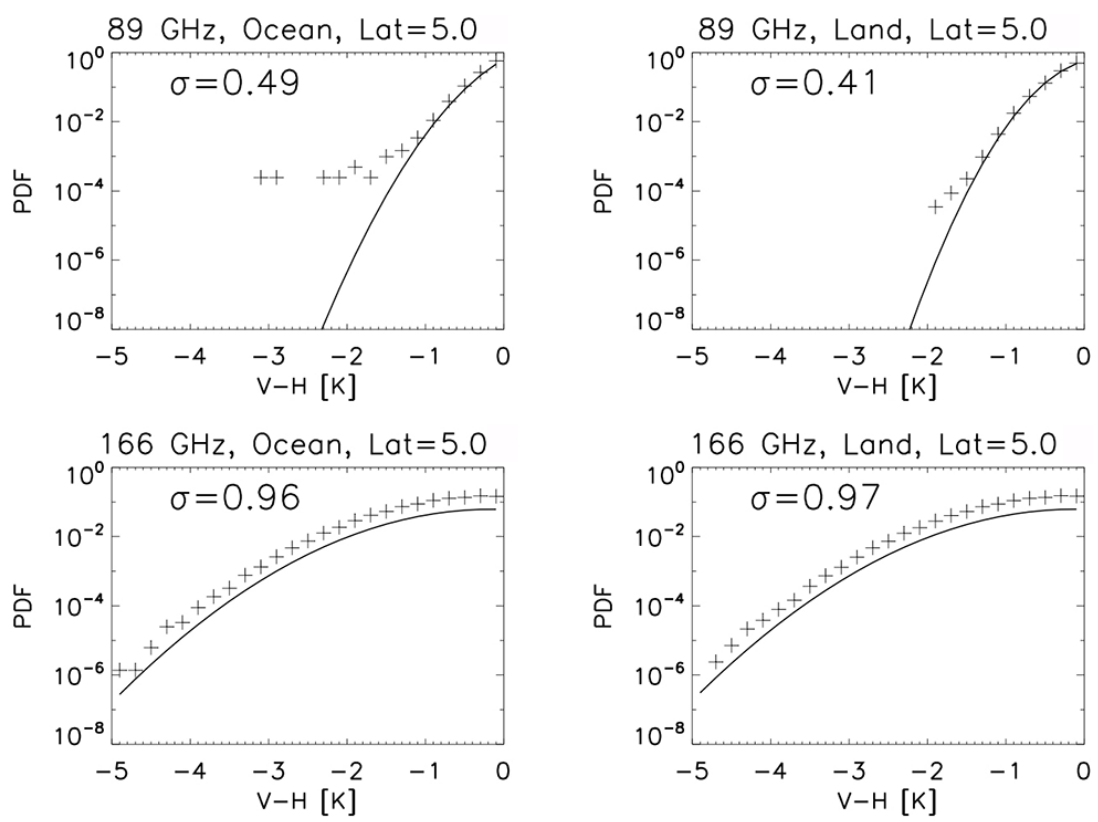

Figure B1. Histogram (cross) of negative PDs based on all GMI observations during January 2015 within the latitude belt of [0, $\left.10^{\circ}\right] \mathrm{N}$ for 89 (top) and $166 \mathrm{GHz}$ (bottom) for ocean (left) and land (right) conditions. The Gaussian distribution fitted curve is plotted in a black solid line, and the standard deviation from the fitted curve is marked in each plot.

(a) $201501,166 \mathrm{GHz}$

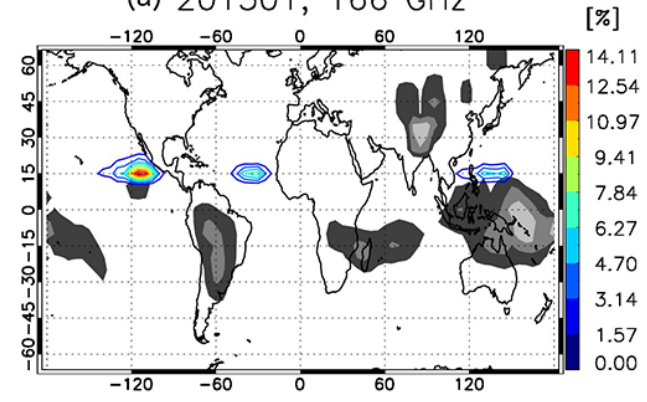

(b) $201507,166 \mathrm{GHz}$

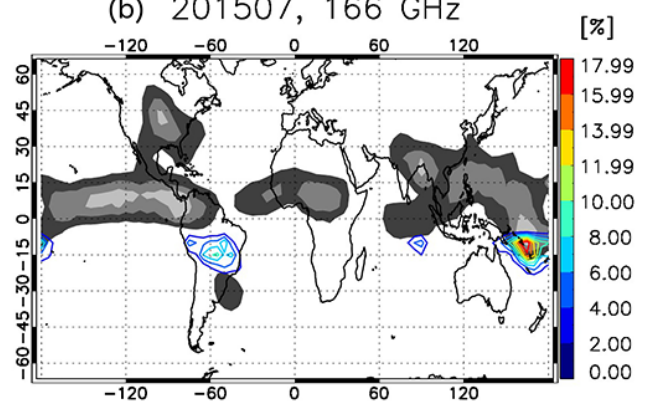

Figure B2. Geographical distribution (colored contours) of negative PD occurrence frequency during January (a) and July (b) 2015 for $166 \mathrm{GHz}$. Gray shades marked the occurrence frequency of $\mathrm{PD}-\mathrm{TB}_{\mathrm{V}}<160 \mathrm{~K}$ scenes, which is essentially equivalent to the occurrence frequency of deep convections, except that the signal over the Tibetan Plateau in panel (a) is probably induced by surface contamination. 


\section{Appendix C: PD-TBV relationship at high latitudes}

Figure $\mathrm{C} 1$ shows the 2-D PDF distribution from the same month's climatology as Fig. 3, except that it is from another mid-latitude bin. Compared with Fig. 3, one can see very similar behavior of the PDF peak-connected lines. But the surface signal starts to emerge at $166 \mathrm{GHz}$ at mid-latitude, as shown by the warm branch in the bottom panels of Fig. C1. The $3 \sigma$ threshold method is proven here to be able to effectively exclude the surface signal in the $\mathrm{PD}-\mathrm{TB}_{\mathrm{V}}$ relationship, although it might be too stringent, especially for $166 \mathrm{GHz}$, as the clear-sky PD is only weakly dependent on the ocean surface roughness for this channel.
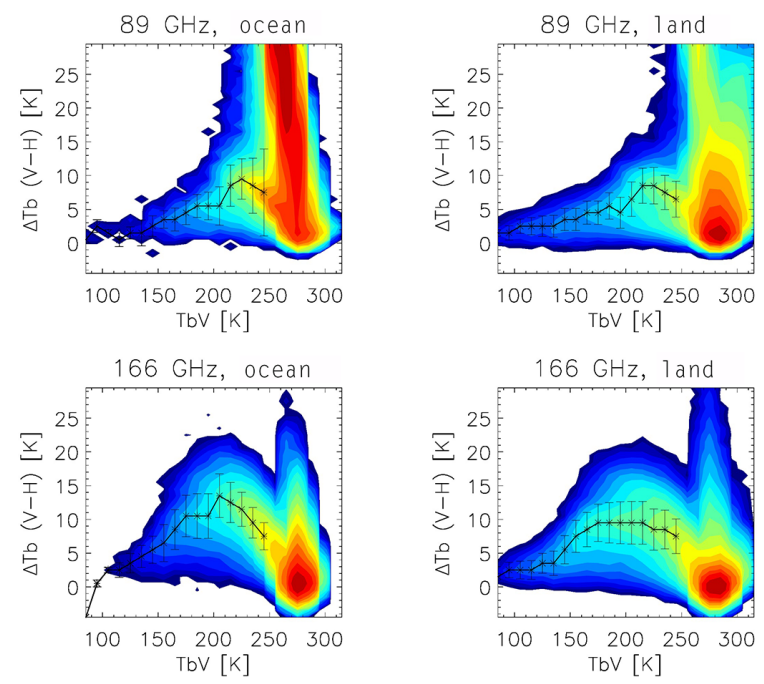

Figure C1. Same as Fig. 3, except for the $\left[45,55^{\circ}\right] \mathrm{N}$ latitudinal belt.

\section{Appendix D: Cloud occurring frequency (CF) derived from the $3 \sigma$ method}

To demonstrate the credibility of the $3 \sigma$ method in screening out the clear-sky scenes, we show the CF of July 2015 from the 89 and $166 \mathrm{GHz}$ channels in Fig. D1. The geographic distribution of CF of anvil and deep convective clouds agrees well with that observed by the CloudSat radar (Sassen et al., 2009). Due to the stringent criteria set by the $3 \sigma$ method, many cirrus scenes are classified as clear-sky scenes, and therefore cirrus cloud CF is obviously biased low using this method.


Figure D1. Cloudy-sky cloud occurring frequency (CF) by applying the $3 \sigma$ method from the GMI's 89 and $166 \mathrm{GHz}$ observations during July 2015. 
Competing interests. The authors declare that they have no conflict of interest.

Acknowledgements. We thank Frank Evans for providing the RT4 code with GMI configuration, and help on interpreting the CoSSIR data. We are also grateful to Ben Johnson, Stephen Munchak and Paul Racette for helpful discussions. Jeffrey Piepmeier and Rachael Kroodsma are acknowledged for assisting in the interpretation of the GMI's channel noises. Two anonymous reviewers' and Yana Mentrok's insightful comments and suggestions are highly appreciated. This work is supported by the NASA NNH12ZDA001N-INVEST fund.

Edited by: H. Wang

Reviewed by: two anonymous referees

\section{References}

Cecil, D. J., Buechler, D. E., and Blakeslee, R. J.: Gridded lightning climatology from TRMM-LIS and OTD: Dataset description, Atmos. Res., 135-136, 404-414, 2014.

Chen, X.: Polarization signature in Micro-Wave Humidity Sounder Window Channels, Master Thesis, Florida State University, 2014.

Comstock, J. M., D’Entremont, R., DeSlover, D., Mace, G. G., Matrosov, S. Y., McFarlane, S. A., Minnis, P., Mitchell, D., Sassen, K., Shupe, M. D., Turner, D. D., and Wang, Z.: An intercomparison of microphysical retrieval algorithms for uppertropospheric ice clouds, B. Am. Meteorol. Soc., 88, 191-204, doi:10.1175/BAMS-88-2-191, 2007.

Czekala, H.: Effects of particle shape and orientation on polarized microwave radiation for off-nadir problems, Geophys. Res. Lett., 25, 1669-1672, 1998.

Davis, C. P., Wu, D. L., Emde, C., Jiang, J. H., Cofield, R. E., and Harwood, R. S.: Cirrus induced polarization in $122 \mathrm{GHz}$ aura Microwave Limb Sounder radiances, Geophys. Res. Lett., 32, L14806, doi:10.1029/2005GL022681, 2005.

Davis, C. P., Evans, K. F., Buehler, S. A., Wu, D. L., and Pumphrey, H. C.: 3-D polarised simulations of space-borne passive $\mathrm{mm} / \mathrm{sub}-$ mm midlatitude cirrus observations: a case study, Atmos. Chem. Phys., 7, 4149-4158, doi:10.5194/acp-7-4149-2007, 2007.

Defer, E., Galligani, V. S., Prigent, C., and Jimenez, C.: First observations of polarized scattering over ice clouds at closeto-millimeter wavelengths $(157 \mathrm{GHz})$ with MADRAS on board the Megha-Tropiques mission, J. Geophys. Res.-Atmos., 119, 12301-12316, doi:10.1002/2014JD022353, 2014.

Evans, K. F. and Stephens, G. L.: Microwave radiative transfer through clouds composed of realistically shaped ice crystals. Part II: Remote Sensing of Ice Clouds, J. Atmos. Sci., 52, 20582072, 1995.

Evans, K. F., Wang, J. R., Racette, P. E., Heymsfield, G., and Li, L.: Ice Cloud Retrievals and Analysis with Data from the Conical Scanning Submillimeter Imaging Radiometer and the Cloud Radar System during CRYSTAL-FACE, J. Appl. Meteorol., 44, 839-859, 2005.

Evans, K. F., Wang, J. R., O'C Starr, D., Heymsfield, G., Li, L., Tian, L., Lawson, R. P., Heymsfield, A. J., and Bansemer, A.: Ice hydrometeor profile retrieval algorithm for high-frequency microwave radiometers: application to the CoSSIR instrument during TC4, Atmos. Meas. Tech., 5, 2277-2306, doi:10.5194/amt5-2277-2012, 2012.

Galligani, V. S., Prigent, C., Defer, E., Jimenez, C., and Eriksson, P.: The impact of the melting layer on the passive microwave cloud scattering signal observed from satellites: A study using TRMM microwave passive and active measurements, J. Geophys. Res.Atmos., 118, 5667-5678, 2013.

Gedzelman, S. D. and Arnold, R.: The form of cyclonic precipitation and its thermal impact, Mon. Weather Rev., 121, 1957-1978, 1994.

Gong, J. and Wu, D. L.: View-angle-dependent AIRS cloudiness and radiance variance: Analysis and interpretation, J. Geophys. Res.-Atmos., 118, 2327-2339, 2013.

Gong, J. and Wu, D. L.: CloudSat-constrained cloud ice water path and cloud top height retrievals from MHS 157 and $183.3 \mathrm{GHz}$ radiances, Atmos. Meas. Tech., 7, 1873-1890, doi:10.5194/amt7-1873-2014, 2014.

Homeyer, C. R. and Kumjian, M. R.: Microphysical characteristics of overshooting convection from polarimetric radar observations, J. Atmos. Sci., 72, 870-891, 2015.

Houze, R. A.: Cloud Dynamics, Academic Press, 104, ISBN: 9780123742667, 2014.

Hu, Y.: Depolarization ratio-effective lidar ratio relation: Theoretical basis for space lidar cloud phase discrimination, Geophys. Res. Lett., 34, L11812, doi:10.1029/2007GL029584, 2007.

Igel, A. L., van den Heever, S. C., Naud, C. M., Saleeby, S. M., and Posselt, D. J.: Sensitivity of warm frontal processes to cloudnucleating aerosol concentrations, J. Atmos. Sci., 70, 17681783, doi:10.1175/JAS-D-12-0170.1, 2013.

Iguchi, T., Seto, S., Meneghini, R., Yoshida, N., Awaka, J., and Kubota, T.: GPM/DPR Level-2 Algorithm Theoretical Basis Document, https://pmm.nasa.gov/sites/default/files/document_files/ ATBD_GPM_DPR_n3_dec15.pdf, 2010.

Li, J.-L. F., Waliser, D. E., Stephens, G., Lee, S., L’Ecuyer, T., Kato, S., Loeb, N., and Ma, H.-Y.: Characterizing and understanding radiation budget biases in CMIP3/CMIP5 GCMs, contemporary GCM, and reanalysis, J. Geophys. Res.-Atmos., 118, 8166-8184, doi:10.1002/jgrd.50378, 2013.

Libbrecht, K. G.: The physics of snow crystals, Rep. Prog. Phys., 68, 855-895, doi:10.1088/0034-4885/68/4/R03, 2005.

Liu, G.: A database of microwave single-scattering properties for nonspherical ice particles, B. Am. Meteorol. Soc., 89, 1563, doi:10.1175/2008BAMS2486.1, 2008.

Meissner, T. and Wentz, F. J.: The emissivity of the ocean surface between 6 and $90 \mathrm{GHz}$ over a large range of wind speeds and earth incidence angles, IEEE T. Geosci. Remote, 50, 3004-3026, 2012.

Miao, J., Johnsen, K.-P., Buehler, S., and Kokhanovsky, A.: The potential of polarization measurements from space at $\mathrm{mm}$ and sub$\mathrm{mm}$ wavelengths for determining cirrus cloud parameters, Atmos. Chem. Phys., 3, 39-48, doi:10.5194/acp-3-39-2003, 2003.

Mishchenko, M. I.: Extinction and polarization of transmitted light by partially aligned non-spherical grains, Astrophys. J., 367, 561-574, 1991.

Mishchenko, M. I., Travis, L. D., and Lacis, A. A.: Scattering, Absorption, and Emission of Light by Small Particles, Cambridge University Press, Cambridge, UK, 2002. 
NASA: Precipitation Processing System (PPS), NASA GPM GMI Level 1B Algorithm Theoretical Basis Document (ATBD), NASA Goddard Space Flight Center, available at: https://pmm.nasa.gov/sites/default/files/document_files/ GMIL1B_ATBD.pdf, November, 2010.

NASA: Precipitation Processing System (PPS), NASA GPM GMI Level 1C Algorithm Theoretical Basis Document (ATBD), Version 1.4, NASA Goddard Space Flight Center, available at: https://pmm.nasa.gov/sites/default/files/document_files/ GMIL1B_ATBD.pdf, March, 2015.

Noel, V. and Chepfer, H.: A global view of horizontally oriented crystals in ice clouds from Cloud-Aerosol Lidar and Infrared Pathfinder Satellite Observation (CALIPSO), J. Geophys. Res.Atmos., 115, doi:10.1029/2009JD012365, 2010.

Oue, M., Ohigashi, T., Tsuboki, K., and Nakakita, E.: Vertical distribution of precipitation particles in Baiu frontal stratiform intense rainfall around Okinawa Island, Japan, J. Geophys. Res.-Atmos., 120, 5622-5637, doi:10.1002/2014JD022712, 2015.

Prigent, C., Pardo, J. R., Mishchenko, M. I., and Rossow, W. B.: Microwave polarized signatures generated within cloud systems: Special Sensor Microwave Imager (SSM/I) observations interpreted with radiative transfer simulations, J. Geophys. Res., 106, 28243-28258, 2001.

Prigent, C., Defer, E., Pardo, J. R., Pearl, C., Rossow, W. B., and Pinty, J.-P.: Relations of polarized scattering signatures observed by the TRMM Microwave Instrument with electrical processes in cloud systems, Geophys. Res. Lett., 32, L04810, doi:10.1029/2004GL022225, 2005.

Rutledge, S. A. and Hobbs, P.: The mesoscale and microscale structure and organization of clouds and precipitation in mid-latitude cyclones, 8, a model for the seeder-feeder process in warmfrontal rainbands, J. Atmos. Sci., 40, 1185-1206, 1983.

Sassen, K., Wang, Z., and Liu, D.: Cirrus clouds and deep convection in the tropics: Insights from CALIPSO and CloudSat, J. Geophys. Res., 114, D00H06, doi:10.1029/2009JD011916, 2009.

Skofronick-Jackson, G. M. and Wang, J. R.: The Estimation of Hydrometeor Profiles from Wideband Microwave Observations, J. Appl. Meteor., 39, 1645-1656, 2000.

Soden, B. J. and Lanzante, J. R.: An assessment of satellite and radiosonde climatologies of upper-tropospheric water vapor, J. Climate, 9, 1235-1250, 1996.

Tao, Z., Santanello, J. A., Chin, M., Zhou, S., Tan, Q., Kemp, E. M., and Peters-Lidard, C. D.: Effect of land cover on atmospheric processes and air quality over the continental United States a NASA Unified WRF (NU-WRF) model study, Atmos. Chem. Phys., 13, 6207-6226, doi:10.5194/acp-13-6207-2013, 2013.
Waliser, D. E., Moncrieff, M. W., Burridge, D., Fink, A. H., Gochis, D., Goswami, B. N., Guan, B., Harr, P., Heming, J., Hsu, H.-H., Jakob, C., Janiga, M., Johnson, R., Jones, S., Knippertz, P., Marengo, J., Nguyen, H., Pope, M., Serra, Y., Thorncroft, C., Wheeler, M., Wood, R., and Yuter, S.: The "Year" of Tropical Convection (May 2008-April 2010): Climate Variability and Weather Highlights, B. Am Meteorol. Soc., doi:10.1175/2011BAMS3095.1, 2012.

Wallace, J. M. and Hobbs, P. V.: Atmospheric Science: an introductory survey (second edition), ISBN: 978-0-12-732951-2, 2006.

Wu, D. L. and Jiang, J. H.: EOS MLS Algorithm Theoretical Basis for Cloud Measurements, Technical Report, Jet Propulsion Laboratory, D-19299/CL\#04-2160, A TBD-MLS-06, available at: https://mls.jpl.nasa.gov/data/eos_cloud_atbd.pdf, 2004.

Wu, D. L., Austin, R. T., Deng, M., Durden, S. L., Heymsfield, A. J., Jiang, J. H., Lambert, A., Li, J.-L., Livesey, N. J., McFarqhuar, G. M., Pittman, J. V., Stephens, G. L., Tanelli, S., Vane, D. G., and Waliser, D. E.: Comparisons of global cloud ice from MLS, CloudSat, and correlative data sets, J. Geophys. Res., 114, D00A24, doi:10.1029/2008JD009946, 2009.

Xie, X.: Polarized signals from oriented frozen hydrometeors using passive microwave radiometry, $\mathrm{PhD}$ dissertation, Universität zu Köln, Köln, Germany, 2012.

Xie, X. and Miao, J.: Polarization difference due to nonrandomly oriented ice particles at millimeter/submillimeter waveband, J. Quant. Spectrosc. Ra., 112, 1090-1098, 2011.

Xie, X., Löhnert, U., Kneifel, S., and Crewell, S.: Snow particle orientation observed by ground-based microwave radiometry, J. Geophys. Res., 117, D02206, doi:10.1029/2011JD016369, 2012.

Yang, P., Wendisch, M., Bi, L., Kattawar, G., Mishchenko, M., and $\mathrm{Hu}, \mathrm{Y}$.: Dependence of extinction cross-section on incident polarization state and particle orientation, J. Quant. Spectrosc. Ra., 112, 2035-2039, 2011.

Yang, P., Bi, L., Baum, B. A., Liou, K.-N., Kattawar, G. W., Mishchenko, M. I., and Cole, B.: Spectrally Consistent Scattering, Absorption, and Polarization Properties of Atmospheric Ice Crystals at Wavelengths from 0.2 to $100 \mu \mathrm{m}$, J. Atmos. Sci., 70, 330-347, 2013.

Zhou, C., Yang, P., Dessler, A. E., Hu, Y., and Baum, B. A.: Study of horizontally oriented ice crystals with CALIPSO observations and comparison with Monte Carlo radiative transfer simulations, J. Appl. Meteorol. Clim., 51, 1426-1439, 2012.

Zhou, C., Yang, P., Dessler, A. E., and Liang, F.: Statistical properties of horizontally oriented plates in optically thick clouds from satellite observations, IEEE Geosci. Remote Sens. Soc., doi:10.1109/LGRS.2012.2227451, 2013. 